UNIVERSIDADE DE SÃO PAULO

FACULDADE DE MEDICINA DE RIBEIRÃO PRETO

THAÍSA MARA LEAL CINTRA RODRIGUES

INDENIZAÇÕES EM OBSTETRÍCIA - ESTUDO DE CASOS E ANÁLISE DO DISCURSO COLETIVO DAS DECISÕES DO STJ

Ribeirão Preto

2016 
THAÍSA MARA LEAL CINTRA RODRIGUES

\section{INDENIZAÇÕES EM OBSTETRÍCIA - ESTUDO DE CASOS E ANÁLISE DO DISCURSO COLETIVO DAS DECISÕES DO STJ}

Dissertação apresentada à Faculdade de Medicina de Ribeirão Preto da Universidade de São Paulo, como parte integrante das exigências para a obtenção do título de Mestre em Ciências.

Área de Concentração: Gestão de Organizações de Saúde.

Orientador Professor Doutor Altacilio Aparecido Nunes.

Ribeirão Preto

2016 
AUTORIZO A REPRODUÇÃO E DIVULGAÇÃO TOTAL OU PARCIAL DESTE TRABALHO, POR QUALQUER MEIO CONVENCIONAL OU ELETRÔNICO, PARA FINS DE ESTUDO E PESQUISA, DESDE QUE CITADA A FONTE.

Rodrigues, Thaísa Mara Leal Cintra.

Indenizações em obstetrícia - estudo de casos e análise do discurso coletivo das decisões do STJ. Ribeirão Preto, 2016

$67 \mathrm{p}$.

Dissertação de Mestrado, apresentada à Faculdade de Medicina de Ribeirão Preto/USP. Área de concentração: Gestão de Organizações de Saúde.

Orientador: Prof. Dr. Nunes, Altacilio Aparecido.

1. Obstetrícia. 2. Jurisprudência. 3. Erros médicos. 4. Responsabilidade civil. 5. Estudo de casos e discurso do sujeito coletivo. 


\section{FOLHA DE APROVAÇÃO}

Thaísa Mara Leal Cintra Rodrigues. Indenizações em obstetrícia - estudo de casos e análise do discurso coletivo das decisões do STJ

Dissertação apresentada à Faculdade de Medicina de Ribeirão Preto da Universidade de São Paulo, como parte integrante das exigências para a obtenção do título de mestre em Ciências.

Área de Concentração: Gestão de Organizações de Saúde

\section{BANCA EXAMINADORA}

Prof. Dr.

Instituição:

Assinatura:

Prof. Dr.

Instituição:

Assinatura:

Prof. Dr.

Instituição:

Assinatura:

Prof. Dr.

Instituição:

Assinatura: 


\section{AGRADECIMENTOS}

Agradeço a Deus, Meu Pai, Mestre e Educador por me conceder força, coragem, esperança sempre para não desistir dos meus sonhos!

Agradeço ao meu orientador, prof. Altacílio, pelo acolhimento e todo o aprendizado!

Agradeço ao meu marido Heitor, amor, amigo e parceiro para toda a vida. Obrigada pela compreensão, incentivo e auxílio nos momentos difíceis!

Agradeço à minha família, meu pai, que mesmo não pertencendo a este mundo, se faz presente em espírito. À minha mãe, meu sogro Teo, minhas irmãs e sobrinhas, obrigada pelo apoio e carinho! 


\section{SUMÁRIO}

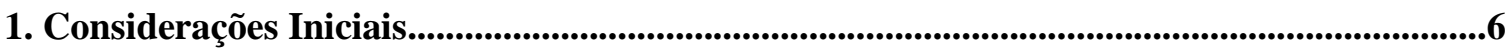

2. Artigo 1 - Indenizações em obstetrícia - estudo de casos das decisões do

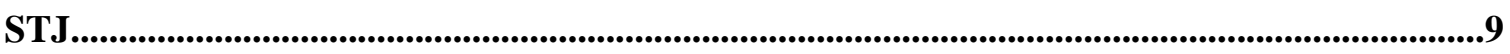

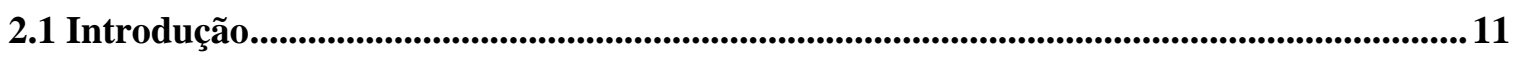

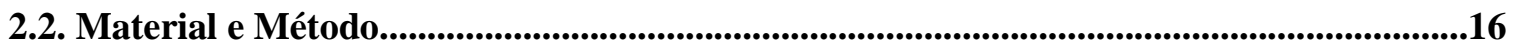

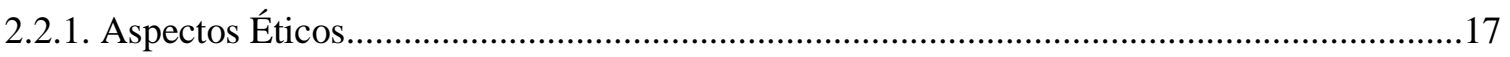

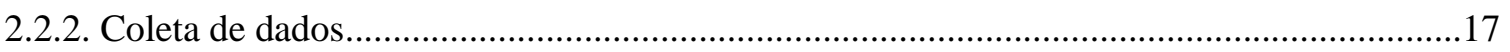

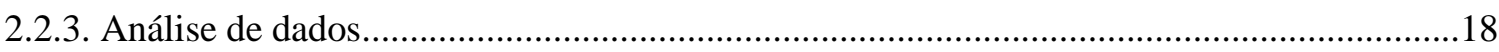

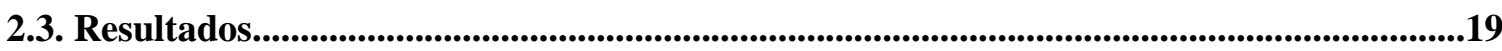

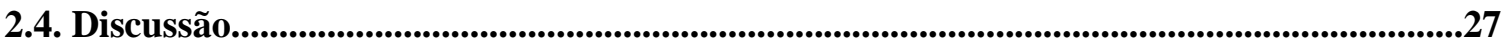

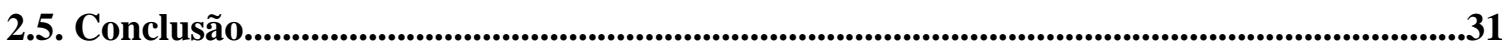

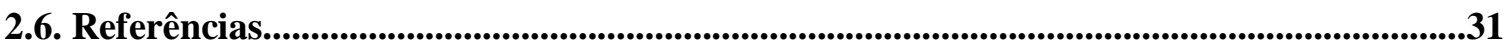

3. Artigo 2 - Análise do discurso do STJ acerca das indenizações que envolvem o parto

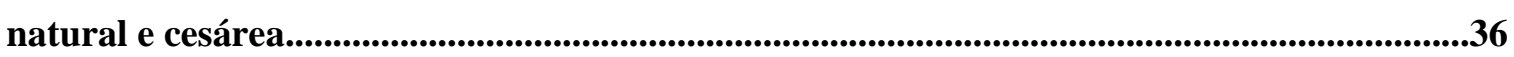

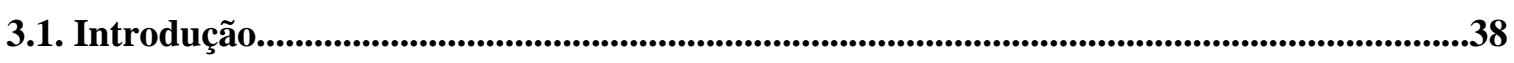

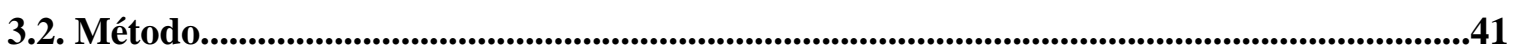

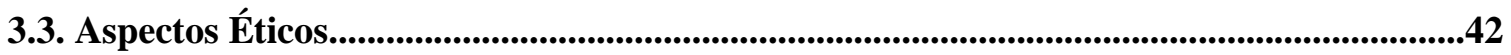

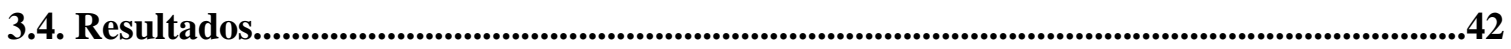

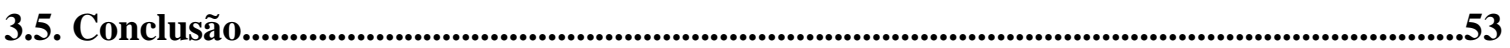

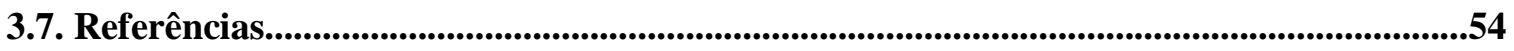

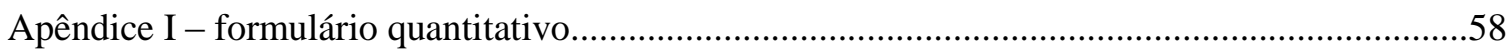

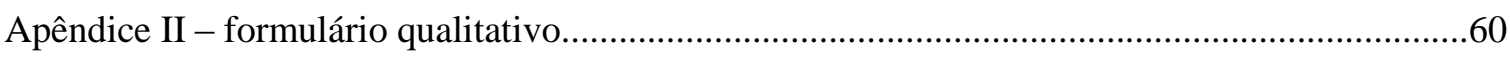

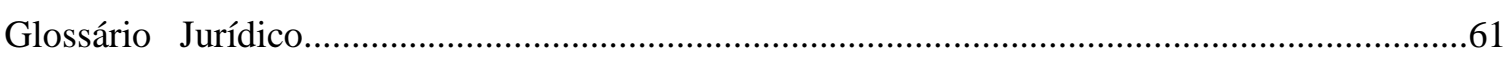




\section{LISTA DE TABELAS}

Tabela 1 - Representação das especialidades médicas demandadas, julgadas pelo Superior Tribunal de Justiça, entre 2003 a 2013.

Tabela 2 - Comparação por ano de julgamento, Estado do ajuizamento da ação, os réus que figuraram no polo passivo e o tipo de parto realizado

Tabela 3 - Associação do parto cesárea, às causas dos danos, às sequelas sofridas e tipo de hospital .20

Tabela 4 - Associação do parto normal às causas dos danos, às sequelas sofridas e tipo de hospital, se público ou privado.

Tabela 5 - Associação ao tipo de prova produzida frente à procedência ou improcedência da ação, assim como a natureza da indenização pleiteada e o valor da condenação. .25

Tabela 6 - Fatores de riscos para encefalopatia do recém-nascido. .29 


\section{LISTA DE GRÁFICOS}

Gráfico 1- Evolução do número de cesarianas no Brasil de 1996 a 2011

Gráfico 2 - Evolução da mortalidade materna segundo causas obstétricas e causas específicas de óbito de 1990 a 2011 .13

Gráfico 3 - Organograma do Poder Judiciário. .63 


\section{LISTA DE ABREVIATURAS E SIGLAS}

STJ Superior Tribunal de Justiça

SUS Sistema Único de Saúde

FEBRASGO Federação Brasileira de Ginecologia e Obstetrícia

ODM Objetivo de Desenvolvimento do Milênio

FIOCRUZ Fundação Osvaldo Cruz

MS Ministério da Saúde

MBE Medicina Baseada em Evidências

OMS Organização Mundial da Saúde

CRM Conselho Regional de Medicina

CFM Conselho Federal de Medicina

ONU Organização das Nações Unidas

DSC Discurso do Sujeito Coletivo 
A peculiaridade da profissão médica não encontra limites apenas na atividade desenvolvida, mas na resposta do organismo humano e, desta forma, nem todo mau resultado pode ser rotulado como erro médico".

(Acórdão $n^{\circ} 113.057$ do Superior Tribunal de Justiça).

\section{Considerações Iniciais}

O trabalho teve como foco o estudo da jurisprudência do Superior Tribunal de Justiça acerca das ações judiciais indenizatórias que debatem a prática médica obstétrica. A pesquisa resultou na elaboração de dois artigos científicos que retratam o entendimento dos Ministros do STJ sob o prisma médico e jurídico dos casos disponíveis para análise, cujos elementos das decisões demonstraram inúmeras variáveis, tais como fatos, provas, responsabilidade médica, natureza das indenizações, causas de excludente da responsabilidade médica, dentre outras, capazes de esclarecer o entendimento externado por esta Corte.

A análise jurisprudencial dos 21 (vinte e um) casos selecionados para a pesquisa, de maneira geral, revela a relação médico-paciente, a responsabilidade civil e obrigacional dos centros de saúde e do médico obstetra ao lidar com a vida materna e fetal, as angústias e dificuldades enfrentadas pelos envolvidos no processo gestacional e como a medicina baseada em evidências (MBE) pode contribuir para minimizar os riscos ou as chances de sequela e morte materna e/ou fetal.

A iniciativa do trabalho surgiu com a notícia de regulamentação por parte do Poder Público e Privado de controle de partos realizados nas redes de saúde. Há muito tem se discutido o excesso de realização de cesáreas no Brasil, o que fez surgir diversos movimentos de incentivo ao parto natural, humanizado e até mesmo o domiciliar, que de longa data estava praticamente extinto.

Primeiramente, foi realizada a revisão da literatura acerca de estudos jurisprudenciais que abrangiam o tema proposto. Observou-se que ainda são escassos os trabalhos que utilizam como base a pesquisa jurisprudencial na área da saúde. Sobre este tipo de pesquisa, como base da teoria discursiva do Direito, Habermas, um filósofo e sociólogo alemão já havia reconhecido como forma de comunicação racional entre os sujeitos das relações, as decisões judiciais que se baseiam em interpretações válidas e legítimas, oriundas de normas devidamente fundamentadas, capazes de intervir direta ou indiretamente na sociedade de forma positiva, uma vez que são discutidos 
casos concretos vivenciados num meio social dinâmico e em constante crescimento e evolução. Mas para isto, as tomadas de decisões jurídicas sugerem incluir, sobretudo o diálogo interdisciplinar.

A pesquisa constatou a importância da proximidade entre as esferas médica e jurídica, especialmente no que tange aos avanços humanos, sociais, técnicos e científicos encontrados nas diferentes especialidades da área da saúde.

No área obstétrica não é diferente. Cada vez mais é preciso aliar os diálogos interdisciplinares aos sujeitos envolvidos nos processos, além de fomentar a discussão acerca das técnicas e procedimentos médicos estruturados, a bioética e o direito quando da análise de riscos na tomadas de decisões, sobretudo as práticas que possam comprometer a vida humana.

O artigo 1, elaborado sob o prisma do direito médico, identificou inúmeras variáveis que indicam as principais causas da má prática médica na obstetrícia; quais as indenizações pleiteadas; quais os instrumentos probatórios são mais prevalentes ao convencimento dos Julgadores; a influência que exercem os fatos e as provas produzidas no desfecho da demanda (procedência ou improcedência); quais os atos culposos praticados pelos médicos obstetras e se eles poderiam ser evitados; dentre outras.

O estudo cruzado de 21 casos do Superior Tribunal de Justiça, disponíveis para análise, observou que é mínimo o número de demandas judiciais indenizatórias na especialidade obstétrica que são apreciadas pelos Tribunais Superiores, conquanto, não significa dizer que os julgamentos desta Corte não reflitam o pensamento do Poder Judiciário Brasileiro, vez que o seu papel é uniformizar e pacificar os entendimentos das instâncias inferiores.

Dessa forma, os casos concretos em estudo são importantes para mapear e desenvolver as estratégias que permitam adequação nas searas pública e privada, tanto nas questões relacionadas à saúde da mulher e da criança que está sendo gerada, quanto dos profissionais de saúde que atuam na área, principalmente quando se propõe a mudança de cultura do parto no país, sendo que a relação de confiança e transparência deve ser sempre exercida entre as partes, a fim de contribuir no processo gestacional e puerperal, independentemente das decisões tomadas.

O Ministério da Saúde e a Agência Nacional de Saúde têm instituído políticas e medidas rigorosas relacionadas à atenção humanizada ao parto, porém é necessária a adoção de um sistema organizado, dotado de conhecimento e atitudes que visam a promoção e assistência integral direcionada à mãe e ao nascituro.

Ocorre que a especialidade obstétrica tem maior demanda judicial indenizatória em decorrência da má prática médica, segundo informações extraídas do Conselho Federal de Medicina. Também foram levantados dados em revisão bibliográfica e recentes pesquisas científicas da área que corroboram a prevalência dos processos judiciais em face dos obstetras. 
$\mathrm{O}$ artigo 2 foi elaborado utilizando a mesma base de dados do artigo 1, conquanto foi utilizado o método da análise do discurso coletivo, cujo viés jurídico foi ressaltado, a fim de demonstrar o posicionamento dominante nos discursos proferidos pelos Ministros do STJ. Este por sua vez, traduz com mais detalhes e informações, uma vez que se baseiam em normas legais, fundamentos jurídicos e correntes jurisprudenciais prevalentes.

Nesta pesquisa foram abordados assuntos relacionados à MBE na área obstétrica, especialmente aos procedimentos decorrentes do parto natural e a cesárea. Foram demonstrados que a tomada de decisões baseadas nas melhores evidências são sempre a forma mais segura para o profissional da saúde e os pacientes, a fim de minimizar os riscos e evitar os danos e sequelas muitas vezes irreversíveis.

Foram reveladas no artigo algumas práticas da medicina defensiva pelos médicos obstetras, isso porque sua atuação muitas vezes tem como prioridade o menor risco para si. Esta mudança de atitude tem sido justificada pelos inúmeros processos judiciais indenizatórios sofridos, cujos valores das indenizações arbitradas são elevados, assim como o desgaste emocional e a angústia são muitas vezes vivenciados pelos médicos que praticam a obstetrícia.

Os discursos dos julgadores do STJ tratam de questões que favorecem o estudo qualiquantitativo proposto, cujos dados e debates obtidos demonstraram os principais posicionamentos dos Ministros da Corte, no tocante à responsabilidade objetiva do Hospital; a responsabilidade subjetiva do médico; a responsabilidade solidária do médico e hospital; as possíveis falhas na prestação de serviços com base na relação de consumo; as provas produzidas e o convencimento dos Julgadores; as possíveis más práticas dos procedimentos do parto cesáreo e natural, assim como o fato da técnica, dano, culpa e nexo causal. 


\section{Artigo 1}

\section{Indenizações em obstetrícia: Estudo de casos das decisões do STJ}

\section{Indemnities in obstetrics: Case studies of the High Court of Justice decisions}

\section{Resumo}

Introdução: A completa dependência fisiológica do feto em relação à mãe exige do médico obstetra, excelência na assistência integral à mulher no período gravídico e puerperal, assim como no desenvolvimento e integridade do feto. É imprescindível, portanto, o aperfeiçoamento do ensino médico, a fim de que desde a formação, o profissional possa desenvolver habilidades que permitam identificar e compreender as situações de riscos que envolvem a gestante e a criança que está sendo gerada. Objetivo: Identificar nas decisões do Superior Tribunal de Justiça, o resumo dos fatos, objeto do litígio e as principais causas que geram a má-prática médica na obstetrícia. Método: Trata-se de estudo descritivo e investigativo de casos julgados pelo Superior Tribunal de Justiça no período de 2004 a 2014 que debatem a prática de médicos obstetras. Resultados: Foram extraídos 99 (noventa e nove) decisões do site do STJ acerca das indenizações por erro médico. O critério de seleção para os casos relacionados resultou em 21 decisões apreciadas pelo STJ em "Recurso Especial” e em "Agravo Regimental no Agravo em Recurso Especial". O estudo demonstrou que o Rio de Janeiro é o Estado da Federação Brasileira com maior ativismo judicial nas ações indenizatórias decorrentes da prática médica obstétrica (28,6\%). Em seguida, estão os Estados de São Paulo e Minas Gerais com 14,3\%, predominando a região Sudeste do país. No tocante aos réus que figuraram no polo passivo das demandas, $38,1 \%$ eram médicos e hospitais. A pesquisa verificou que $71 \%$ das supostas falhas médicas obstétricas que originam as ações indenizatórias ocorreram durante a realização do parto natural, e a cesariana em $29 \%$ dos casos. A principal causa dos danos relatados nas decisões foi o período expulsivo prolongado, sendo a segunda causa de danos, os traumatismos. A produção da prova pericial se mostrou essencial, em virtude dos casos demandarem maior especificação técnica de outros profissionais, especialmente, o perito médico nomeado pelo juiz. Dos julgamentos das decisões, $71 \%$ foram procedentes, sendo três casos improcedentes, duas ações foram julgadas extintas em razão da ilegitimidade de parte e da prescrição, e em um dos casos, a ação retornou à origem para novo julgamento. Conclusão: Em que pesem as recentes pesquisas realizadas no Brasil demonstrarem que a cesariana oferece maiores riscos para a parturiente e o feto, os resultados obtidos no trabalho revelam que os danos fetais que resultaram em sequelas irreversíveis no nascituro foram recorrentes nos casos relacionados ao parto natural.

Palavras - Chaves: Jurisprudência, Erro Médico, Obstetrícia. 


\begin{abstract}
Introduction: The fetal physiological dependence on the mother requires the obstetrician, excellence in care to women during pregnancy and postpartum period, as well as in the development and integrity of the fetus. It is imperative, therefore, the improvement of medical education, so that since the formation, the trader can develop skills to identify and understand the risk situations involving the mother and the child that is being generated. Objective: To identify the decisions of the High Court of Justice, the summary of the facts of the dispute object and the main causes that generate the medical malpractice in obstetrics. Method: This is a descriptive and investigative study of cases tried by the High Court of Justice from 2004 to 2014 debating the practice of obstetricians. Results: Ninety nine decisions were extracted of STJ site about medical malpractice. The selection criteria for the related cases resulted in 21 decisions considered by the Supreme Court in "special appeal" and "the Appeal on interlocutory appeal in special appeal". The study showed that Rio de Janeiro is the Brazilian state with the greatest judicial activism in claims for damages resulting from obstetric medical practice (28.6\%), followed by São Paulo and Minas Gerais States, with $14.3 \%$, predominating the southeast region of the country. With regard to defendants who figured in the demands, $38.1 \%$ were doctors and hospitals. The survey found that $71 \%$ of the alleged obstetric medical failures for damages occurred during the course of natural childbirth, while cesarean delivery was in $29 \%$ of cases. The production of expert evidence aid proved essential, because cases demand higher technical specification than other professionals, especially the medical expert appointed by the court. Of the judgments of decisions, $71 \%$ were successful, three cases were unfounded, two actions were extinct, and one case, the action returned to source for new judgment. Conclusion: Despite the recent studies conducted in Brazil shows that the cesarean section offers greater risk to the mother and the fetus, the results obtained in the study reveals that fetal damage resulting in irreversible consequences on the unborn child were plaintiffs in the cases related to natural childbirth.
\end{abstract}

Key Words: Jurisprudence, Medical Error, Obstetrics. 


\section{Introdução}

A Organização Mundial da Saúde há mais de quinze anos coloca a maternidade segura como uma de suas prioridades, ao buscar sempre as melhores evidências científicas disponíveis, a fim de aprimorar o atendimento profissional qualificado na gestação, assim como a humanização do parto. Para tanto, os serviços devem estar adequadamente estruturados para permitir que a vida materna e fetal seja protegida integralmente, seja com intervenções médicas imediatamente instituídas, seja com um sistema de referência, eficaz e atuante ${ }^{1}$.

Dessa forma, necessária a implantação de projetos e políticas públicas que visem a diminuição das barreiras para a assistência materna de qualidade e disponibilidade de serviços obstétricos, adequadamente aparelhados e com profissionais treinados e preparados, dirigidos à redução das mortes maternas e proteção da saúde e integridade do recém-nascido. Os obstetras, independente de qualquer outro fator, podem contribuir positivamente nesse processo, procurando a excelência ao atendimento à mulher e à criança que está sendo gerada, seja durante o pré-parto, o parto, quando predominam as mortes e sequelas irreversíveis, e o pós-parto imediato ${ }^{1}$.

Estima-se que 287.000 mortes maternas ocorreram em todo o mundo em $2010^{2}$, sendo que mais de 50 milhões de mulheres sofrem doenças ou sequelas relacionadas com a gravidez, e pelo menos 1.200.000 recém-nascidos morrem por complicações durante o ciclo gravídico-puerperal ${ }^{3}$. No Brasil, a morte de mulheres durante a gravidez, o parto ou o puerpério (período de 42 dias após o parto) reduziu de forma acentuada. Em 1990, em média ocorriam 141 óbitos por 100 mil nascidos vivos, sendo que em 2011, a taxa ficou em menos de 64 óbitos por 100 mil nascidos vivos $^{4}$. Recentemente, foi realizada pela Fundação Oswaldo Cruz, em parceria com o Ministério da Saúde, uma pesquisa denominada "Nascer Brasil". Este estudo com 23.940 mulheres, durante o período de fevereiro de 2011 a outubro de 2012, mostrou que quase $54 \%$ dos nascimentos eram por cesarianas (Figura 1), ao passo que as recomendações da OMS são para que apenas de $10 \%$ a $15 \%$ dos partos sejam realizados por meio deste procedimento cirúrgico ${ }^{5,6}$. 
Gráfico 1 - Evolução do número de cesarianas no Brasil de 1996 a 2011.

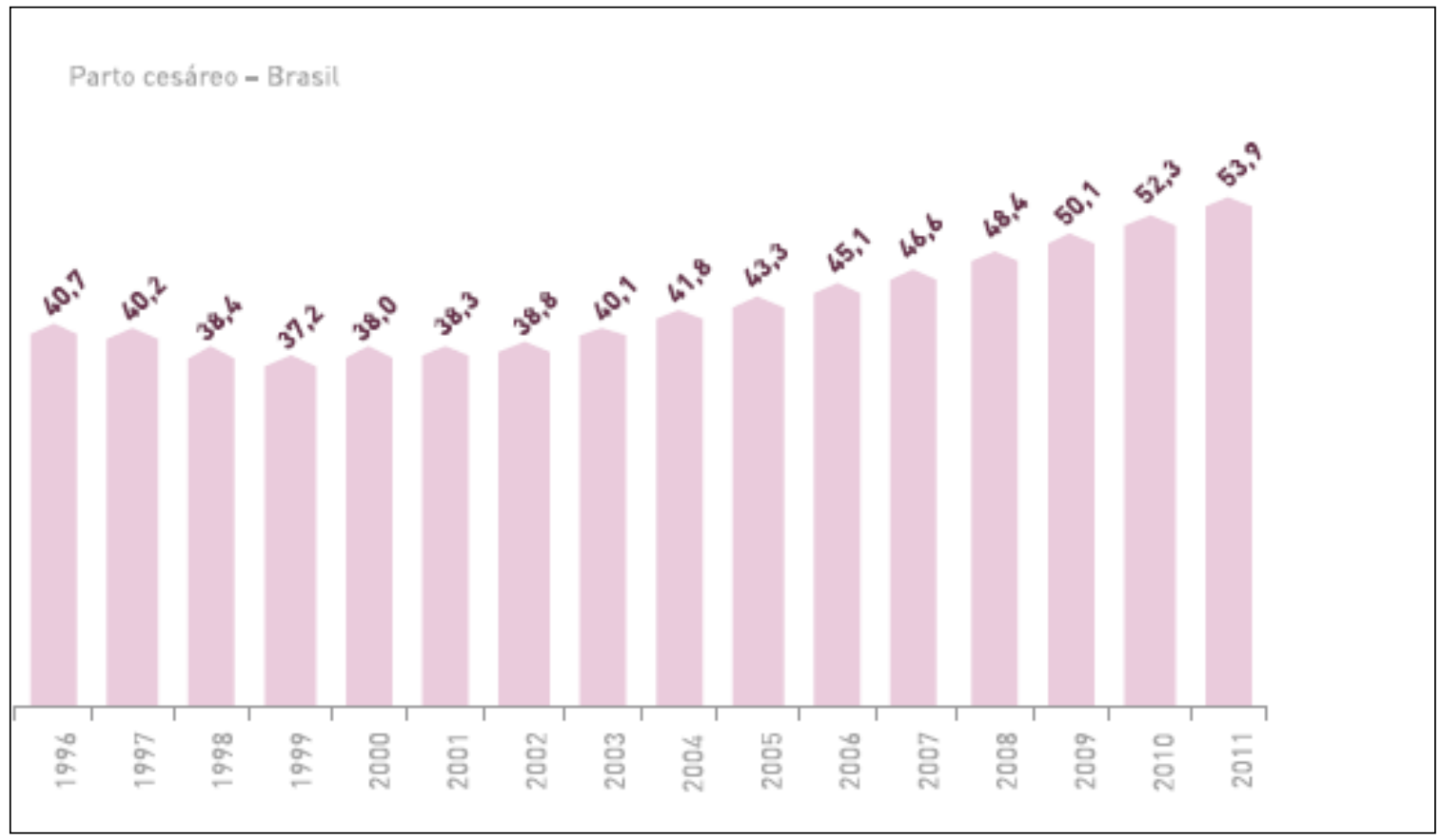

Fonte: Objetivos de Desenvolvimento do Milênio: $5^{\circ}$ Relatório Nacional de Acompanhamento - Maio de 2014. Pesquisa "Nascer no Brasil".

No gráfico 2, de acordo com dados também extraídos do $5^{\circ}$ Relatório Nacional de Acompanhamento, apontam que a mortalidade materna, segundo o grupo de causas diretas (RRM direta - Risco de Mortalidade Materna Direta), tais como: hipertensão, hemorragias, infecção puerperal e aborto demonstram um declínio considerável entre os anos de 1990 a 2011, ao passo que as causas indiretas, ou seja, Risco de Mortalidade Materna Indireta (RRM indireta), ainda contam com número crescente de mortes maternas ${ }^{5,6}$. 
Gráfico 2 - Causas de mortalidade materna por causas específicas no Brasil de 1990, 2000 e 2011

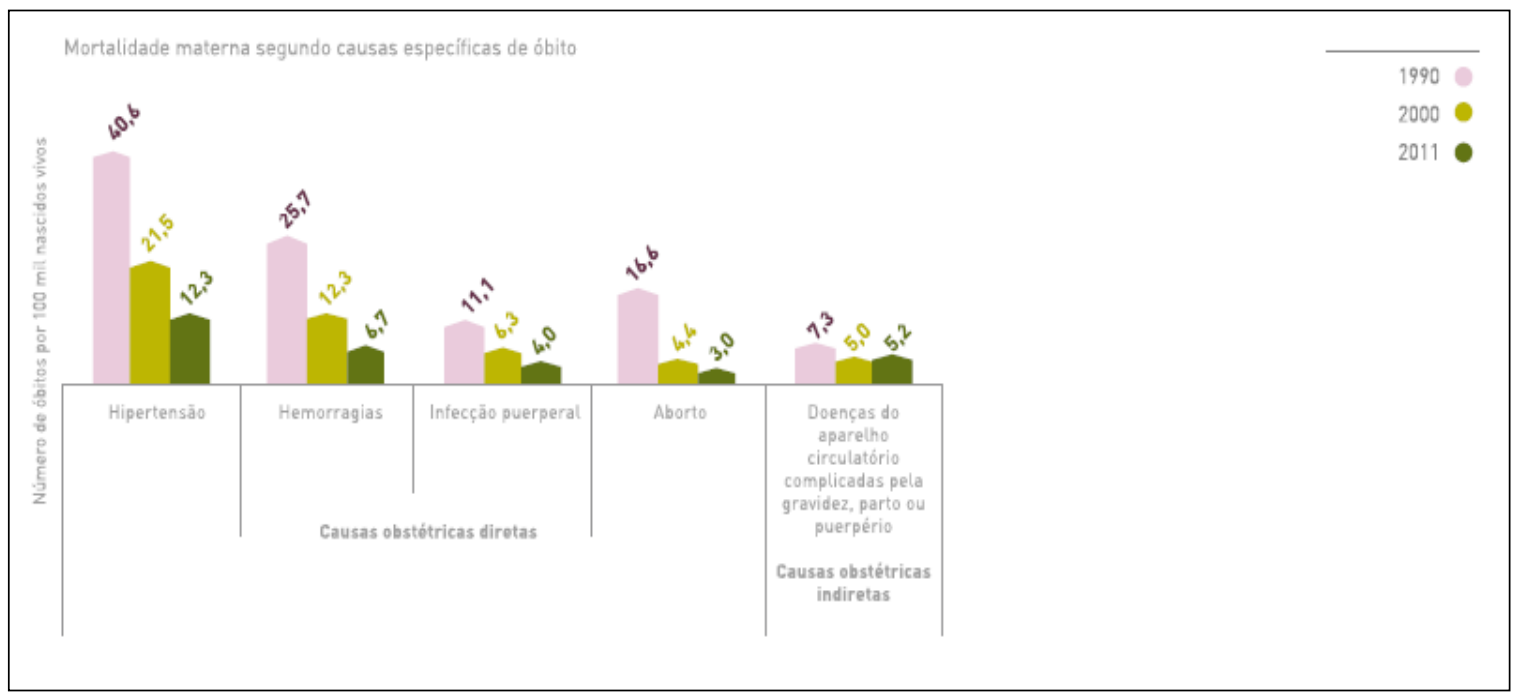

Fonte: Objetivos de Desenvolvimento do Milênio: $5^{\circ}$ Relatório Nacional de Acompanhamento - Maio de 2014. Pesquisa "Nascer no Brasil".

Outra grande preocupação é o aumento da prematuridade no Brasil. A proporção de nascimentos antes de 37 semanas de gestação, encontrada neste estudo foi de 11,3\%, 50\% a mais do que em países desenvolvidos. Em relação aos recém-nascidos com 37 ou 38 semanas gestacionais, a proporção foi de $35 \%$, o que explica o número elevado de cesarianas agendadas antes do início do trabalho de parto, especialmente no setor privado. A Fiocruz entende que embora não sejam considerados prematuros, são nascituros que poderiam ganhar mais peso e maturidade se tivessem a chance de chegar a 39 semanas ou mais de gestação $0^{5,6}$.

Segundo o $5^{\circ}$ Relatório Nacional de Acompanhamento das Metas, a elevada percentagem de partos cesáreos representa um grande desafio para a política de saúde nos setores públicos e privados $^{7}$. A Agência Nacional de Saúde Suplementar publicou em 07 de janeiro de 2015, a Resolução Normativa 368 que estabelece diretrizes para estímulo do parto normal e a consequente redução de cesarianas desnecessárias. $\mathrm{O}$ artigo $1^{\circ}$ da norma dispõe sobre o direito de acesso à informação das beneficiárias aos percentuais de cesarianas e de partos normais, por operadora, por estabelecimento de saúde e por médico, bem como, sobre a utilização do partograma, do cartão da gestante e da carta de informação à gestante no âmbito da saúde suplementar ${ }^{8}$.

Dessa forma, os resultados do estudo "Nascer no Brasil" são importantíssimos para mapear as estratégias de tomada de decisão dos gestores na elaboração e adequação das políticas públicas, tanto em questões relacionadas à saúde da mulher, quanto dos profissionais de saúde que atuam 
na área. Os dados preocupam não só os organismos de saúde internacionais, como as instituições de saúde brasileiras públicas e privadas que defendem uma mudança na cultura do parto no país 9 .

O Ministério da Saúde tem incentivado de forma insistente a atenção humanizada ao parto, cuja pretensão envolve um conjunto de conhecimento e atitudes que visam a promoção e assistência à parturiente e ao feto, a prevenção da morbimortalidade materna e perinatal e a redução dos danos irreversíveis causados aos pacientes no momento do parto ${ }^{10}$.

Diante desse contexto, todavia, as denúncias relacionadas à prática médica obstétrica e ginecológica apresentadas no Conselho Federal de Medicina são frequentes, sendo quase 30\% do total de queixas, segundo a Federação Brasileira das Associações de Ginecologia e Obstetrícia FEBRASGO ${ }^{11}$.

Isso porque a vida está estritamente ligada a esta área, sendo por sua vez tutelada pela Constituição Federal no seu artigo $5^{\circ}$, caput ${ }^{12}$. Lembrando que a partir da vida e saúde materna, sobretudo, é que dependem o nascimento, a qualidade e a expectativa de vida do feto ${ }^{13}$.

A obstetrícia é a especialidade de maior risco judicial dentro da prática médica, face ao grande número de intercorrências no período pré-natal e nas urgências e emergências no trabalho de parto ${ }^{14}$. Alguns estudos jurisprudenciais atestaram que as práticas médicas podem ser pesquisadas a partir de casos concretos julgados pelo Poder Judiciário. Após a publicação do Código Civil, uma pesquisa realizada com 256 acórdãos proferidos pelo Tribunal do Estado de São Paulo acerca da responsabilidade civil médica, constatou que a maioria das ações são propostas contra os médicos e hospitais $(25,39 \%)$. A especialidade médica mais demandada foi a ginecologia/obstetrícia $(19,9 \%)$, seguida da cirurgia plástica $(7,8 \%)^{14}$.

Outra pesquisa jurisprudencial mais recente analisou nos bancos de dados Medline/ Pubmed, Lilacs e nos processos judiciais de primeira instância referenciados em 16 acórdãos do Tribunal de Justiça do Estado de São Paulo, entre 01 de junho de 2013 e 31 de maio de 2014. O trabalho traçou o perfil das demandas judiciais, cujos autores na sua maioria eram pacientes e cônjuges (50\%), na maior parte dos casos o hospital (56\%) foi o réu, a especialidade médica mais acionada foi a Obstetrícia (81\%) e a Ginecologia ficou com $31 \%$ dos casos; a prova pericial favoreceu o réu, verificou nexo de causalidade em quatro casos (25\%), considerou sem nexo de causalidade nove casos (56\%), sendo estes processos julgados improcedentes na maioria das vezes, as indenizações arbitradas nos casos de condenação do réu variaram entre $R$ \$ 40.000,00 e $\mathrm{R} \$ 466.500,00^{15}$.

A tabela a seguir representa as especialidades médicas com maior índice de demandas judiciais indenizatórias julgadas pelo STJ nos anos de 2003 a $2013^{16}$. 
Tabela 1 - Representação das especialidades médicas demandadas, julgadas pelo Superior Tribunal de Justiça, entre 2003 a 2013.

\begin{tabular}{lr}
\hline Especialidade Médica & Percentagem \\
\hline Ginecologia e Obstetrícia & $27,08 \%$ \\
Ortopedia & $12,50 \%$ \\
Cirurgia Plástica & $10,42 \%$ \\
Anestesia & $6,25 \%$ \\
Urologia & $4,17 \%$ \\
Oftalmologia & $4,17 \%$ \\
Cirurgia Geral & $3,13 \%$ \\
Pediatria & $3,13 \%$ \\
Cirurgia Pediátrica & $1,04 \%$ \\
Clínica Médica & $1,04 \%$ \\
Hematologia & $1,04 \%$ \\
Neurocirurgia & $1,04 \%$ \\
Neurologia & $1,04 \%$ \\
Oncologia & $1,04 \%$ \\
Otorrinolaringologia & $1,04 \%$ \\
Radiologia & $1,04 \%$ \\
Cirurgia Vascular & $1,04 \%$ \\
\hline
\end{tabular}

As possíveis falhas médicas na obstetrícia podem ser decorrentes de diversas razões e as sequelas são na maioria, irreversíveis à vida dos pacientes, assim como os danos, muitas vezes, são fatais. Em que pesem existentes as intercorrências, a saúde e a vida são bens considerados invioláveis, e por outro lado existe um profissional, humano, falível, que apesar de utilizar muitas vezes as melhores técnicas, expõe o paciente a riscos ${ }^{17}$. Assim, se existe o ato danoso contra o paciente, os médicos, em geral, estão sujeitos a responderem por seus atos.

O primeiro julgamento pode ocorrer na esfera administrativa pelos Conselhos de Medicina, cujas ações se baseiam no Código de Ética Médica, no artigo 29 que dispõe: "é vedado ao médico praticar atos profissionais danosos ao paciente, que possam ser caracterizados como imperícia, imprudência ou negligência" ${ }^{\prime 18}$.

O segundo se refere à esfera judicial, na qual os médicos estão sujeitos a serem julgados na Justiça Comum, ou seja, os conflitos humanos e sociais são submetidos ao Estado-Juiz, o que ao final fornece elementos de percepção, com atuação crescente em questões ligadas ao sistema de saúde brasileiro, cujos preceitos e normas estão dispostos nos Códigos Penal e Civil ${ }^{19}$. Nesse sentido, o presente trabalho identificou como o STJ tem se posicionado ao longo de 10 (dez) 
anos, acerca da prática médica em obstetrícia, e como a resolução destes conflitos pode ser oferecida para diminuir as falhas e os processos jurídicos.

Foi realizado um estudo retrospectivo das demandas apreciadas e julgadas pelo STJ nos anos de 2004 a 2014, acerca das indenizações relacionadas à prática médica em obstetrícia. A partir dos dados extraídos das decisões, foram analisadas as principais causas deste tipo de litígio sob a ótica dos fundamentos legais e jurídicos, considerando-se a prevalência dos danos no momento do parto e em quais tipos de procedimento: cesariana ou natural; quais as provas produzidas que mais convenceram os julgadores nas suas decisões; a média de valores das condenações; o índice de procedência, improcedência e reforma das decisões nas diferentes instâncias, dentre outras informações relevantes que traçam o perfil deste tipo de demanda.

\section{Material e Métodos}

Trata-se de pesquisa descritiva baseada em estudo de casos, uma vez que as pesquisas quanti-qualitativas podem ser utilizadas com base no estudo jurisprudencial ${ }^{20}$ e possuem como fonte principal de dados, documentos oficiais (escritos) do Poder Judiciário. Portanto, esclarecese que a reiteração das decisões é o que se denomina jurisprudência, termo que vem do latim jurisprudentia (jus "justo" + prudentia "prudência") e significa o "conjunto de decisões proferidas pelos tribunais nos casos concretos submetidos a seu julgamento"21.

A pesquisa jurisprudencial revela o desenvolvimento do próprio conhecimento científico jurídico ao aproximá-lo de outras ciências sociais. A utilização de uma abordagem institucionalista na metodologia de pesquisa permite identificar o papel do Poder Judiciário como gerador do comportamento dos agentes diretamente envolvidos em suas decisões ${ }^{22}$.

Com base na estrutura dos julgados, foi realizado um trabalho investigativo de casos, cuja análise jurisprudencial discursiva decorrerá dos elementos que compõem as decisões: a) o relatório, que contém o nome das partes, a síntese do pedido e da resposta do réu, bem como o registro das principais ocorrências havidas no andamento do processo; b) os fundamentos, em que o julgador analisará as questões de fato e de direito; c) o dispositivo, em que o julgador resolverá as questões, que as partes lhe submeterem.

Optou-se pela análise da jurisprudência do Superior Tribunal de Justiça em razão desta Corte resolver, respectivamente, questões diretamente relacionadas com as normas federais em última instância, e uniformizarem o entendimento a respeito da matéria foco principal da pesquisa em caráter nacional, servindo de parâmetro para a resolução das demandas judiciais pelos juízes de primeira e segunda instância. 
Os estudos com decisões judiciais podem ser classificados nas tipologias de Gerring de Estudos de Casos ou Estudos Cruzados de Casos (Cross Case Studies) ${ }^{23}$. Nos estudos cruzados de casos, por sua vez, o foco da pesquisa muda de um caso único para uma seleção de $\operatorname{casos}^{23}$.

O presente trabalho utilizou o estudo cruzado de casos, uma vez que foram analisadas 21 (vinte e uma) decisões prolatadas no período de 2004 a 2014, extraídos do site do STJ, cuja matéria versa sobre o erro médico na obstetrícia. Dentre os principais questionamentos relativos ao estudo que envolve o erro médico são em síntese: quais os fatos, causas e elementos probatórios das decisões; o tipo de prova levada em consideração pelo magistrado na fundamentação do acórdão; os diplomas legais mais citados nas decisões; os precedentes judiciais mais utilizados pelos julgadores, o que e quem influencia os juízes - fatos, provas, doutrina ou jurisprudência, quais são os fundamentos presentes nos discursos dos tribunais para resolução dos conflitos que tratam da responsabilidade civil do médico obstetra.

Posto isso, foram realizadas duas etapas. A primeira para mapeamento dos fatos e coleta de dados extraídos dos julgados e a segunda terá como foco a análise qualitativa das decisões, com base nos posicionamentos, motivações e juízos emitidos pelos julgadores nos casos disponíveis.

\section{Aspectos Éticos}

O presente projeto de pesquisa foi submetido ao Comitê de Ética em Pesquisa do Hospital das Clínicas da Faculdade de Medicina de Ribeirão Preto - HCFMRP/USP, sendo aprovado, com dispensa do Termo de Consentimento Livre e Esclarecido, uma vez que o trabalho trata de estudo de casos não envolvendo pesquisa com seres humanos, apenas análise e coleta de dados públicos extraídos do site do Poder Judiciário.

\section{Coleta de dados}

O primeiro levantamento de dados foi quantitativo, a partir da coleta de dados que abrange a busca dos fatos e informações objetivas extraídas dos acórdãos. Ocorreram duas etapas de busca das decisões que abrangem o tema.

Primeiramente, a seleção dos acórdãos foi realizada em um trabalho acadêmico ${ }^{16}$, cujos resultados apontaram um universo de 90 (noventa) julgados extraídos do site do STJ num período de 2003 a 2013, que debatem sobre erros médicos, sendo 12 (doze) deles, referente às práticas obstétricas relacionadas ao parto. O levantamento dos acórdãos foi realizado no campo "pesquisa livre", utilizando os seguintes termos: "erro médico"; "médico"; "paciente"; "profissional da 
saúde"; "dano moral"; "dano material" "SUS"; "responsabilidade civil" e "indenização por erro médico", escolheu-se a classe "Recurso Especial" que foram admitidos e julgados pelo STJ.

Num segundo momento, foi realizada uma nova pesquisa, com o objetivo de abranger os casos julgados pelo STJ no período de 2004 a 2014. A busca foi realizada no campo "pesquisa livre" com os seguintes termos: "erro médico" e "parto". O resultado da pesquisa encontrou 13 (treze) decisões em "Recurso Especial” e em "Agravo Regimental no Agravo em Recurso Especial" que foram apreciadas pelo STJ, dos quais 4 (quatro) deles constavam na primeira seleção de acórdãos, o que resultou num total de 21 (vinte e um) julgados.

Após a seleção das decisões, foi identificada a estrutura da decisão, ou seja, qual a sua ementa, relatório, fundamentação e dispositivo, que são requisitos essenciais, para constituição de qualquer decisão judicial.

A ementa é a síntese do acórdão, em que normalmente se resumem objetivamente os seus pontos fundamentais.

O relatório é a parte inicial do acórdão, onde se narram e descrevem os fatos do processo, o direito que está sendo discutido pelas partes e onde se estabelecem os princípios de fato e de direito sobre os quais se construirá o julgamento.

A motivação ou fundamentação resulta da análise feita pelos juízes ou ministros sobre as questões de fato e de direito expostas no relatório, a partir da qual se constroem as bases lógicas para a decisão; é onde se exteriorizam as razões que determinam o convencimento do órgão judicial.

O dispositivo é a parte final do acórdão e consiste na conclusão até então desenvolvido no relatório e na motivação. Caracteriza a manifestação, o posicionamento do Judiciário.

Após a leitura de cada acórdão foram levantados os dados armazenados num formulário elaborado no Microsoft Excel ${ }^{\circledR}$.

\section{Análise de dados}

Após coleta sistemática das informações de cada caso foi possível a consulta a qualquer tópico de pesquisa e eventuais comparações com a análise objetiva dos fatos e dados. Foram avaliados os objetos de investigação, possibilitando identificar os fundamentos utilizados pelos julgadores, o entendimento externado acerca da matéria debatida, identificando correntes da jurisprudência do STJ. Os formulários estratégicos cruzaram diversas informações da pesquisa, tais como: fato, dano, nexo causal, objeto, pedidos, fundamentação utilizada pelos julgadores; provas e outros elementos de convicção; valor e natureza das indenizações; dentre outros. 
Para comparação de dados foi empregado o teste de $\mathrm{Z}$ ao se tratar de proporções, enquanto que, na comparação de medidas de tendência central, será empregado o teste $\boldsymbol{t}$ de Student para amostras independentes para médias, bem como, o teste de Mann-Whitney para amostras independentes quando for o caso de medianas. O nível de significância será de $5 \%(\mathrm{p}<0,05)$.

\section{Resultados}

Nas tabelas a seguir podem ser observados os dados coletados por ano do julgamento de cada caso estudado; o Estado do ajuizamento da ação; os réus que figuraram no polo passivo; o tipo de parto realizado; as causas dos danos; as sequelas sofridas e tipo de hospital, se público ou privado; o tipo de prova produzida frente à procedência ou improcedência da ação, assim como a natureza da indenização pleiteada e o valor da condenação. Por conseguinte, serão analisados e discutidos cada caso, conforme os dados apresentados.

Na tabela 1, pode-se observar todos os casos e a distribuição dos mesmos por ano de julgamento, estado da federação de origem, réus do processo e tipo de parto.

Tabela 2 - Comparação por ano de julgamento, Estado do ajuizamento da ação, os réus que figuraram no polo passivo e o tipo de parto realizado.

\begin{tabular}{llllr}
\hline Caso & Ano do julgamento & Estado & Réu (s) & Tipo de Parto \\
\hline $\mathbf{1}$ & & & & \\
$\mathbf{2}$ & 2004 & DF & Médica e Hospital & Cesariana \\
$\mathbf{3}$ & 2006 & RJ & Município do Rio de Janeiro & Natural \\
$\mathbf{4}$ & 2007 & RJ & Município do Rio de Janeiro & Natural \\
$\mathbf{5}$ & 2008 & MT & Hospital e Médicos & Cesariana \\
$\mathbf{6}$ & 2009 & MG & Hospital & Natural \\
$\mathbf{7}$ & 2010 & MG & Hospital e Médico & Natural \\
$\mathbf{8}$ & 2010 & PR & Hospital & Cesariana \\
$\mathbf{9}$ & 2010 & MA & Estado do Maranhão & Cesariana \\
$\mathbf{1 0}$ & 2011 & BA & Hospital e Médico & Natural \\
$\mathbf{1 1}$ & 2011 & PR & Médica & Natural \\
$\mathbf{1 2}$ & 2011 & DF & Médica e Hospital & Natural \\
$\mathbf{1 3}$ & 2011 & RJ & União e Hospital Militar & Natural \\
$\mathbf{1 4}$ & 2011 & MG & Hospital & Natural \\
$\mathbf{1 5}$ & 2011 & RS & Município de Porto Alegre & Natural \\
& 2012 & RJ & Município do Rio de Janeiro e & Natural \\
$\mathbf{1 6}$ & & & Médicos & Cesariana \\
\hline
\end{tabular}




\begin{tabular}{|c|c|c|c|c|}
\hline & & & Médicos & \\
\hline 17 & 2012 & RJ & Médica & Natural \\
\hline 18 & 2013 & RS & $\begin{array}{l}\text { Universidade Federal de Santa } \\
\text { Maria }\end{array}$ & Cesariana \\
\hline 19 & 2014 & SP & Hospital & Natural \\
\hline 20 & 2014 & SP & Fundação Santa Casa & Natural \\
\hline 21 & 2014 & SP & Hospital e médica & Natural \\
\hline
\end{tabular}

O estudo demostrou que nos cinco primeiros anos (2004 a 2009), o número de julgamentos apreciados pelo STJ foi irrisório comparado aos anos posteriores, sendo que em 2011 o total de julgados (6), ultrapassou a soma dos primeiros anos (5). O estudo revelou que o Estado da Federação Brasileira com maior ativismo judicial nas ações indenizatórias decorrentes da prática médica é o Rio de Janeiro, com 28,6\% do total, em seguida estão o Estado de São Paulo e de Minas Gerais com 14,3\% (p>0,05), predominando assim a região Sudeste do país, porém sem significância estatística em relação às demais regiões ( $p>0,05)$.

No tocante aos réus que figuraram no polo passivo das demandas, foi constatado um percentual de $38,1 \%$ dos médicos e hospitais, comparados ao hospital e ao Estado do Rio de Janeiro que figuraram individualmente como réus, totalizando $14,3 \%$ cada um deles ( $p>0,05)$.

As supostas falhas médicas obstétricas que originaram as ações indenizatórias ocorreram em sua maioria durante a realização do parto natural ( $71 \%$ dos casos), enquanto que a cesariana foi em 29\%, assim, comparando-se as proporções de processos considerando-se parto normal versus cesariana, observa-se uma predominância significativa de partos normais $(\mathrm{p}<0,05)$.

$\mathrm{Na}$ tabela 2, se observam os danos e suas respectivas causas decorrentes de cesariana, entre os processos estudados, considerando-se a natureza jurídica do hospital.

Tabela 3 - Associação do parto cesárea, às causas dos danos, às sequelas sofridas e tipo de hospital, se público ou privado.

\begin{tabular}{|c|c|c|c|c|}
\hline $\begin{array}{l}\text { Tipo de } \\
\text { Parto }\end{array}$ & Caso & Causas dos Danos & Danos & Hospital \\
\hline \multirow{4}{*}{ Cesárea } & 1 & $\begin{array}{l}\text { Esquecimento de compressa } \\
\text { cirúrgica no organismo da } \\
\text { parturiente }\end{array}$ & $\begin{array}{l}\text { Mãe sofreu retirada da trompa esquerda; transfusão de } \\
\text { sangue; drenagem }\end{array}$ & Privado \\
\hline & 2 & $\begin{array}{l}\text { Esquecimento de compressa } \\
\text { cirúrgica no organismo da } \\
\text { parturiente }\end{array}$ & $\begin{array}{l}\text { Mãe sofreu septicemia; retirada parcial do útero; } \\
\text { utilizou bolsa de colostomia; perda auditiva e cicatrizes }\end{array}$ & Público \\
\hline & 3 & Prescrição irregular de medicação & Perda do filho e extração do útero materno & Privado \\
\hline & 4 & Demora na realização do parto - & Nascituro sofreu paralisia cerebral tipo hemiparesia à & Público \\
\hline
\end{tabular}




\begin{tabular}{cll} 
& Sofrimento fetal & esquerda \\
$\mathbf{5}$ & $\begin{array}{l}\text { Falta de material adequado para } \\
\text { procedimento cirúrgico }\end{array}$ & $\begin{array}{l}\text { Nascituro sofreu asfixia hipóxico-isquêmica } \\
\text { Mãe sofreu parada cardiorrespiratória e coma } \\
\text { irreversível durante o parto }\end{array}$ \\
\hline Fonte: Autora & Negligência do anestesista & Público
\end{tabular}

A cesariana foi realizada em seis casos estudados, sendo dois deles decorrentes do esquecimento de material cirúrgico durante o procedimento. No primeiro caso, foi constatado pela perícia que quando da primeira cirurgia (cesariana), realizada pela médica nas dependências do hospital, com utilização de serviços e equipamentos deste, foi esquecido corpo estranho no organismo da autora, resultando processo inflamatório e necessidade da extração do útero. A prova documental, de natureza técnico-científica foi incontroversa. Os autos retornaram à origem, uma vez que foi reaberta a oportunidade do hospital comprovar a culpa exclusiva de terceiro (médico).

No caso 2, a ação foi julgada procedente em virtude dos danos físicos, estéticos, morais e materiais (incapacidade funcional parcial) causados à parturiente, sendo que as indenizações neste caso somaram R $\$ 1.275 .000,00$. A vítima submeteu-se à uma cesariana na Maternidade Pública Estadual, ocasião em que foi esquecida uma compressa cirúrgica de 45 centímetros em seu abdômen, o que ocasionou septicemia (infecção generalizada). Em decorrência desse quadro patológico, foi necessária a realização de histerectomia subtotal (retirada parcial do útero), a vítima utilizou bolsa de colostomia pelo período de oito meses, e, ainda, perdeu, parcialmente a capacidade auditiva.

Neste caso, o julgamento revelou que a retirada do útero, impossibilitou a mulher de procriar, afetou o direito de livre decisão do casal, causando dano moral também, ao marido, no que pertine ao planejamento familiar. Também sofreu dano moral o filho recém-nascido, que não teve os cuidados necessários da sua genitora, inclusive não tendo o direito ao aleitamento materno. Foi fixado o valor de 400.000,00 (quatrocentos mil reais) a título de dano moral e R\$ $800.000,00$ (oitocentos mil reais) a titulo de dano estético para a mãe; bem como o valor de dano moral em $\mathrm{R} \$ 50.000,00$ (cinquenta mil reais) para o marido, e $\mathrm{R} \$ 25.000,00$ (vinte e cinco mil reais) para o filho.

No terceiro caso, a prescrição irregular do medicamento provocou inércia uterina, resultando no parto prematuro, pois a gestação encontrava-se no sétimo mês, gozando de saúde perfeita, com evolução dentro da normalidade. Ao ser atendida no hospital, foi prescrito pelo médico daquela instituição o medicamento Voltaren ${ }^{\circledR}$, cuja bula observava como contraindicação, o risco de efeitos colaterais em gestantes, sobretudo a possibilidade de ocasionar inércia uterina 
e/ou fechamento prematuro do canal arterial, acarretando a morte fetal e a extração do útero da parturiente.

No caso 4, a ação foi julgada procedente em primeira e segunda instâncias, mas o STJ reformou a decisão, excluindo a União, sob o argumento de que em decorrência da demora no atendimento ao parto na rede pública nacional (SUS) não se pode responsabilizar a União. O julgamento se pautou em diversos acórdãos análogos, sendo predominante o entendimento de que nos casos envolvendo o Sistema Único de Saúde, a União não tem legitimidade para responder por eventuais danos causados aos profissionais e instituições de saúde vinculados ao SUS.

No quinto caso, a prova pericial concluiu que houve nexo causal, por falta de material necessário e imprescindível à boa condução do parto; a criança apresentou sequelas graves de asfixia hipóxico-isquêmica, ocorrida durante o procedimento; o menor necessitará de acompanhamento multidisciplinar permanente, em instituições especializadas. Há necessidade contínua de neuroestimulação; além de órteses para os membros inferiores. No caso em exame, o Tribunal de origem, ao considerar as circunstâncias do caso concreto, determinou a majoração do quantum indenizatório arbitrado na sentença, de $\mathrm{R} \$ 80.000,00$ (oitenta mil reais) para o montante de R $\$ 100.000,00$ (cem mil reais), a título de indenização por danos morais. Relativamente à quantificação da pensão vitalícia, a mesma foi majorada para 02 (dois) salários mínimos.

No sexto caso, embora a médica obstetra tenha alertado em duas ocasiões a médica anestesista acerca da falta de oxigenação e diminuição do sangramento da paciente, os procedimentos adotados não foram suficientes para impedir o coma irreversível sofrido pela parturiente. No caso, diante da situação do sofrimento fetal, o laudo pericial afirmou que a atuação dos médicos residentes (menor experiência) em procedimentos de maior complexidade exige o acompanhamento de médico especialista do corpo clínico do hospital. O perito concluiu ainda que o ocorrido na gestante deveu-se a complicações anestésico-cirúrgicas, que estatisticamente são exceções, restando evidenciada a negligência do hospital em não disponibilizar um profissional experiente e capacitado.

Os resultados obtidos nos casos de cesariana demonstraram que em quatro deles, os danos causados à parturiente resultaram em sequelas irreversíveis, em todos podendo ser cogitada a atuação negligente dos profissionais médicos, seja pelo esquecimento de corpo estranho durante a cirurgia, seja pela prescrição irregular de medicação durante a realização do parto. As sequelas fetais ocorridas quando da realização da cesariana resultaram em paralisia cerebral e asfixia. Em um dos casos a cesárea foi realizada em decorrência do sofrimento fetal.

Na tabela 3 a seguir, são apresentados os casos referentes aos partos normais, focando nos danos, sequelas e natureza jurídica do hospital de origem. 
Tabela 4 - Associação do parto normal às causas dos danos, às sequelas sofridas e tipo de hospital, se público ou privado.

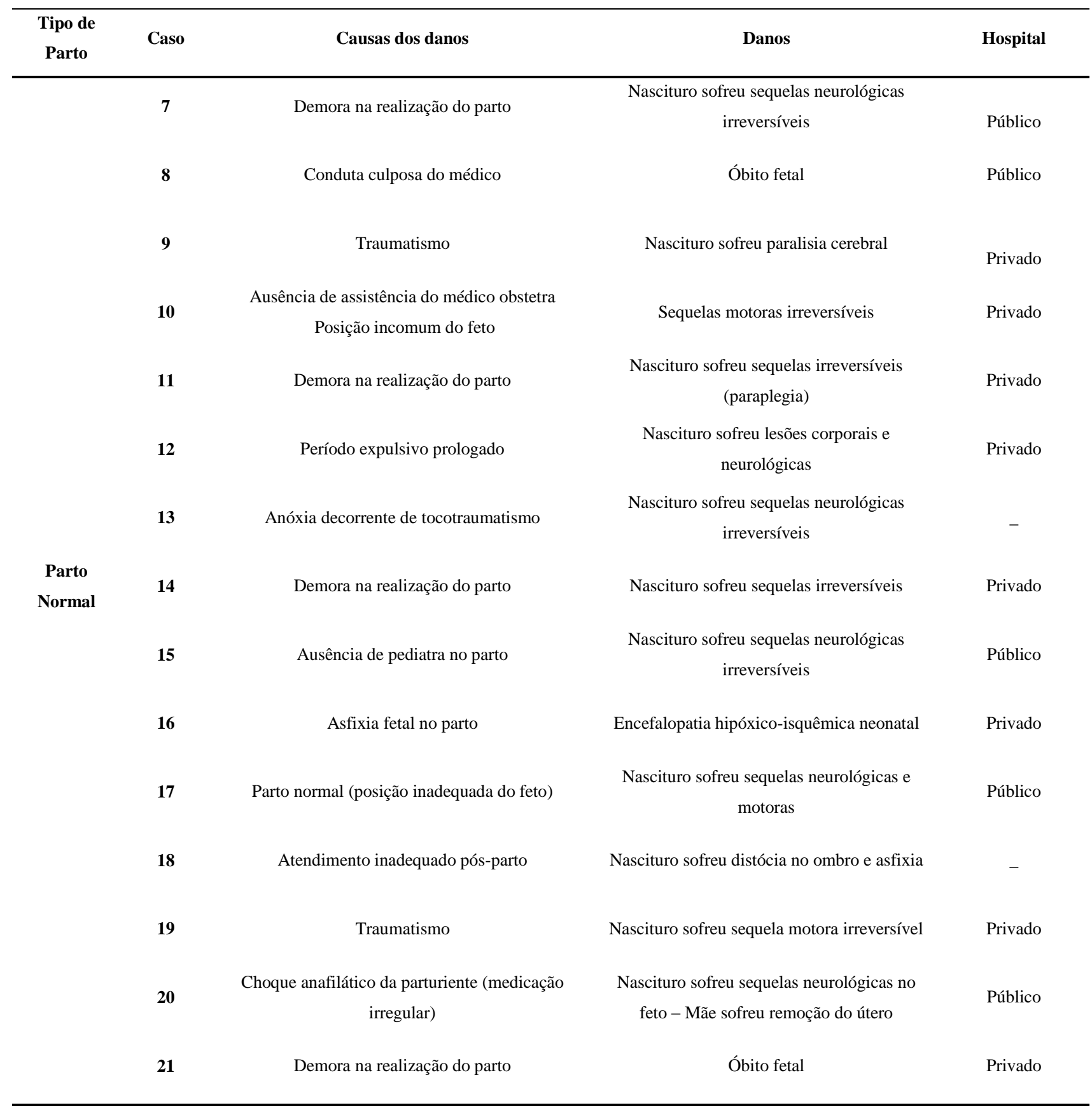

Pode ser observado que a principal causa dos danos constatados durante a realização do parto normal foi a demora no procedimento com período expulsivo prolongado, sendo os traumatismos como segunda causa. As sequelas irreversíveis ocorridas nos recém-nascidos predominaram como os danos mais recorrentes, à frente dos óbitos fetais e dos danos irreversíveis sofridos pela mãe, sendo que a maioria dos partos normais ocorreu em hospitais privados. 
Nos casos relacionados à demora na realização do parto e período expulsivo prolongado (casos 7,11,12,14,21), houve relatos de que o erro consistiu na conduta negligente do médico em não optar pela cesariana, na falta de acompanhamento da frequência cardíaca do feto, retirando-se o profissional da sala de parto no momento crítico da expulsão do recém-nascido. Em outro caso foi demonstrada a negligência do hospital, que se manteve inerte e não acionou seus prepostos para realizar o parto emergencial na mãe da vítima, iniciado tardiamente pela médica que utilizava a estrutura do estabelecimento hospitalar, e assim deve responder solidariamente pelos danos causados à criança, que nasceu com lesões de natureza física e neurológicas irreversíveis. Em outro caso houve falha na prestação do serviço médico hospitalar, o qual deixou de tomar as precauções necessárias e urgentes, de forma a impedir um trabalho de parto tardio, e, consequentemente, sofrimento fetal e sequelas irreversíveis, vindo o nascituro óbito posteriormente.

Dois casos relacionados à demora na realização do parto foram julgados improcedentes. Em um deles, o STJ reformou as decisões de primeiro e segundo grau. Feita perícia, o médico perito não pôde atestar que a patologia apresentada pelo filho da autora era consequência da negligência do médico. Aliás, a perícia foi clara quanto à ausência de negligência, referindo que houve emprego da melhor técnica e diligência, entre as possibilidades de que dispõe o profissional no seu meio de atuação, em auxílio do paciente. Não se podendo olvidar que, mesmo que os profissionais envolvidos empreguem toda sua diligência no ato, ainda assim podem advir reações imprevisíveis e situações inesperadas.

Em outro caso julgado improcedente o laudo foi taxativo ao concluir que os médicos atuaram com todas as precauções necessárias, incluindo a realização do procedimento que se mostrava mais adequado, e que era impossível prever, tampouco prevenir, o dano sobrevindo. Destarte, a conclusão da perícia comprovou que a obrigação de meio da equipe médica foi cumprida e o resultado, ainda que não esperado, não revelou desacerto profissional.

No tocante aos casos relacionados aos traumatismos, duas ações foram julgadas improcedentes. Em um dos casos foi demonstrado nos laudos periciais médicos que a lesão não decorreu de um resultado advindo de um defeito na prestação do serviço, mas sim de evento inesperado e imprevisível durante o procedimento. As perícias realizadas demonstraram que não houve má condução do trabalho de parto, o ocorrido com o complexo mãe-filha foi objeto de uma fatalidade que iniciou normalmente, mas se tornou excessivamente laborioso devido à distócia de ombro da recém-nascida, que lhe causaram sequelas permanentes. Em outro caso, o perito esclareceu que não é possível dizer qual foi a causa da síndrome neurológica do autor, a qual pode decorrer não apenas do alegado traumatismo no parto, mas também de hipertensão 
gestacional, insuficiência placentária, infecção. Assim, baseado em minucioso exame das provas constantes dos autos, concluiu o acórdão não haver prova de nexo causal e de culpa da médica.

A realização do parto natural em posição inadequada do feto ocorreu em dois casos. Um deles conclui pela exclusão dos médicos, em razão da correta conduta praticada, mantendo-se a responsabilidade do município pela falha na prestação do serviço por um de seus agentes (enfermeira obstetriz). Mesmo estando ciente de que a nascitura ainda não se encontrava encaixada na posição adequada, optaram por realizar o parto normal, fazendo-o através do uso do fórceps quando seria necessária a realização de cesariana, advindo desse procedimento sério danos à criança que nasceu sem movimentos, necessitando ser reanimada, com asfixia grave, com edema cerebral e ainda com quadro de hidrocefalia. Contudo, concluiu o expert do juízo que o uso do fórceps não contribuiu para o estado de saúde atual da nascitura, não ocorrendo erro técnico durante sua aplicação porque ausentes sinais de traumatismo fetal pela sua utilização, salientando que na realidade os danos à menor foram ocasionados pela sua indicação tardia, tendo em conta que o que ocasionou a interrupção da oxigenação encefálica foi o hiato temporal (1 hora e 13 minutos) entre a parada de progressão em plano III de Hodge e a extração final da concepta.

A seguir na Tabela 4, podem ser observados o resultado do julgamento, a natureza da indenização, bem como o valor monetário da condenação, considerando-se as provas produzidas.

Tabela 5: Distribuição do tipo de prova produzida frente à procedência ou improcedência da ação, assim como a natureza da indenização pleiteada e o valor da condenação.

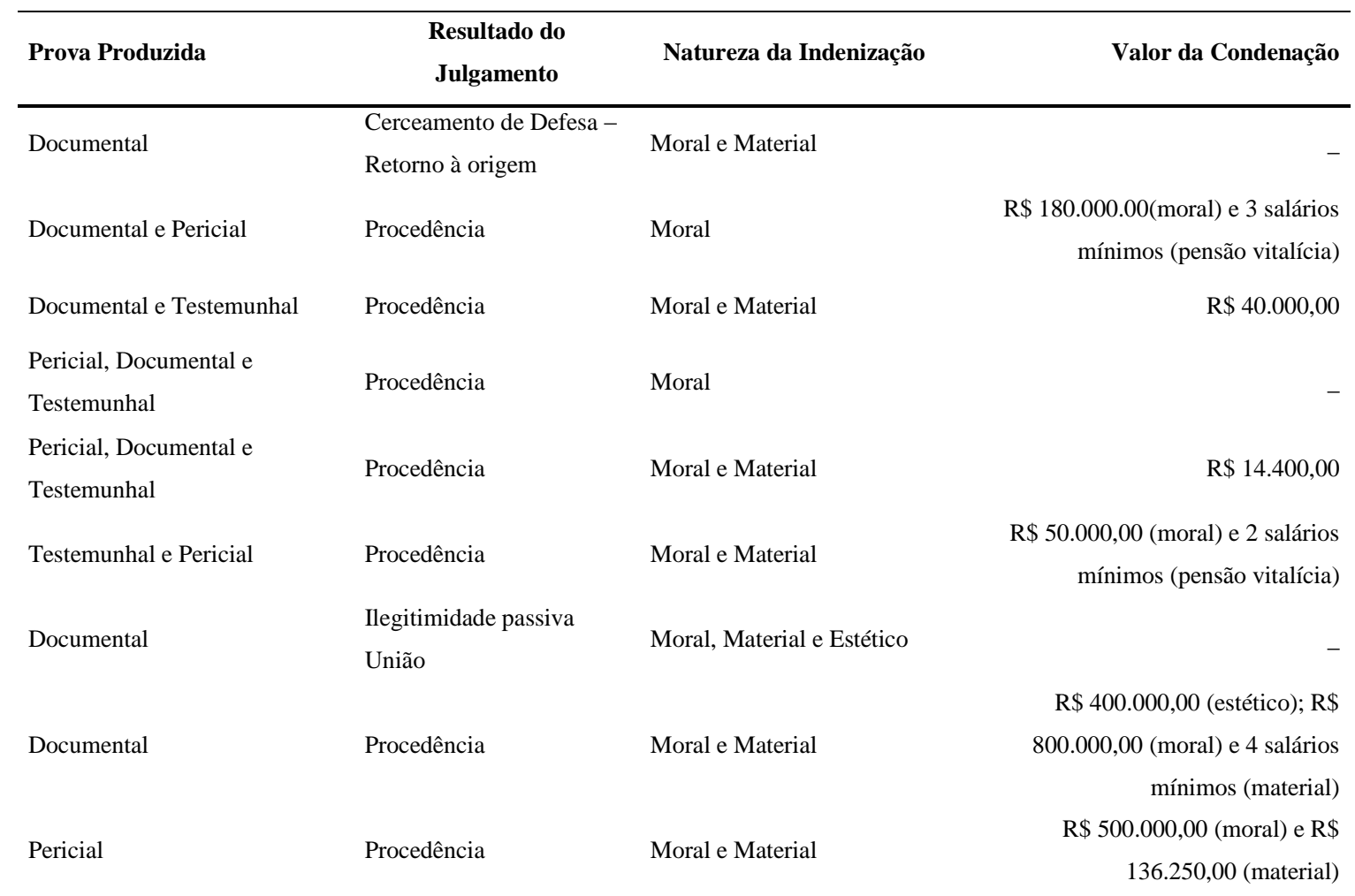




$\begin{array}{lllr}\text { Pericial } & \text { Improcedência } & \text { Moral e Material } & \\ \text { Testemunhal e Pericial } & \text { Procedência } & \text { Moral e Estético } & \text { R } \$ 200,000,00 \text { (moral); R } \$ 46.729,00 \\ \text { (material) e 10 salários mínimos } \\ \text { (pensão) }\end{array}$

Fonte: Autora

Os dados demonstram que os danos morais e materiais foram as indenizações mais pleiteadas nas demandas, face à predominância das sequelas irreversíveis.

As provas têm o papel fundamental em qualquer demanda judicial, a fím de convencer o juiz a julgar procedente ou improcedente $\mathrm{o}(\mathrm{s})$ pedido(s). A prova pericial se destaca como principal meio de prova, em virtude dos casos demandarem maior especificação técnica de outros profissionais, especialmente o médico, cuja função é examinar e elaborar de forma rigorosa os elementos trazidos aos autos (fato, dano, provas documentais, etc). A prova documental já trazida aos autos, antes da realização da perícia passa a ser relevante quando produzida na fase inicial do processo.

A maioria das decisões foi julgada procedente em face do réu, com um percentual de $71 \%$ dos casos. Três dos casos foram julgados improcedentes na decisão de origem, ou revertidas pelos Tribunais, mesmo diante da prova do dano ocorrido. Em todos os casos, a improcedência foi suscitada em razão da ausência do nexo causal entre o dano e a conduta do agente. Nestes casos as provas realizadas nos autos foram essenciais para tal desfecho.

Em um dos casos resultou no cerceamento de defesa. Os autos retornaram à origem para nova produção de prova. O STJ entendeu que em matéria de responsabilidade civil, quando a parte pretende provar a culpa exclusiva de terceiro, não se pode aceitar a simples presunção de 
que a participação da equipe auxiliar do hospital seja responsável, se o fato em si foi o esquecimento de corpo estranho durante a cirurgia, já que a própria cirurgiã afirma que os serviços do hospital foram adequados e satisfatórios. O que sim, não pareceu razoável, em tal circunstância, foi afastar a oportunidade do hospital produzir prova para sustentar a sua alegação de não ter sido responsável pelo evento danoso.

Os valores das condenaçãoes acerca da indenização moral e/ou estética chegaram a quantias altas, sendo que a média dos valores desta natureza foi de $\mathrm{R} \$ 300.000,00$.

Os danos materiais são fixados mediante a incapacidade física constatada na prova pericial, decorrente das sequelas irreversíveis, sendo que a fixação foi apurada com base no salário mínimo. A condenação aos danos materiais chegou até 10 salários mínimos mensais, conforme comprovada a hipossuficiência dos pacientes e as sequelas causadas.

\section{Discussão}

Em que pesem as recentes pesquisas realizadas no Brasil demonstrarem que a cesariana ofereça maiores riscos para a parturiente e o feto ${ }^{5,6,25,26,27}$, os resultados obtidos no trabalho revelam que os danos fetais resultantes em sequelas irreversíveis no nascituro foram recorrentes nos casos relacionados ao parto natural. Os casos analisados sugerem fortemente a prevalência das sequelas causadas nos nascituros durante o pré-parto e parto natural, resultando em treze ocorrências, sendo dois deles com desfecho em óbito, ao passo que em nenhum dos casos analisados foram constatadas sequelas ou danos na parturiente.

Em razão da ocorrência de danos físicos, cerebrais, motores e cognitivos definitivos que geram incapacidade funcional no nascituro, a condenação em danos materiais foi prevalente, chegando a 10 salários mínimos mensais a título de pensão vitalícia. Isso porque, em várias decisões analisadas, os Julgadores se pautaram pelas conseqüências geradas pela incapacidade absoluta e definitiva do recém-nascido lesado. Referidos danos impedem que os nascituros vivam normalmente, pois são muitas vezes incapazes de exercerem no futuro qualquer atividade laborativa, sempre dependendo de familiares e de equipe multidisciplinar de profissionais para assisti-los.

Observa-se, hoje que a cesariana é considerada um procedimento cirúrgico comum em todo mundo. Alguns dados americanos e europeus revelaram aumento de gestações resolvidas por cesariana. As razões incluem: o número crescente de indicações médicas ou pedidos das mulheres grávidas. Isso porque a cesárea eletiva pode diminuir o risco de sofrimento fetal, aspiração de mecônio e ferimentos durante o trabalho. Todavia, foi constatado que a cesariana gera um fator de maior risco de insuficiência respiratória no curso de taquipnéia transitória do recém-nascido, 
síndrome da angústia respiratória e hipertensão pulmonar, tanto para o nascituro a termo quanto para os prematuros lactentes. Como consequência, a criança necessita de uma estadia prolongada na unidade de terapia intensiva, em conjunto com procedimentos médicos avançados e muitas vezes caros, tais como ventilação mecânica (muitas vezes de alta frequência), o tratamento com óxido nítrico e oxigenação por membrana extracorpórea ${ }^{26}$.

Dessa forma, a Associação Norte-Americana de Obstetras e Ginecologistas e a Associação Européia de Medicina Perinatal recomendam que a cesariana apenas deve ser indicada para partos realizados após 39 semanas de gestação, de preferência após as contrações uterinas iniciados e após a avaliação da maturidade pulmonar. Isso inclui também casos de cesarianas eletivas realizadas devido à cesariana anteriores, que são as razões mais frequentes para o procedimento de repetição. As recomendações também restringem as indicações para cesariana em caso de prematuridade significativa o que por sua vez está conectado com indicações mais restritas para reanimação de prematuros extremos e bebês com extremo baixo peso ao nascer ${ }^{26}$.

Ainda sim, as pesquisas realizadas nos Estados Unidos, apontaram que a incidência de cesariana é alarmante ainda que estejam associadas às altas taxas de morbidades maternas e fetais. Assim, estratégias para prevenir cesariana em gestações de baixo risco, são necessárias em mulheres nulíparas, a termo e com feto único. Este trabalho também abordou algumas práticas baseadas em evidências que podem ser utilizadas durante o parto para evitar a cesariana primária, incluindo a paciência da paciente durante o processo do trabalho de parto, ausculta intermitente, suporte de trabalho contínuo, posições verticais e livre mobilidade, práticas de trabalho em segundo plano, como manejar a rotação do feto. Estas práticas de cuidados obstétricos pode, potencialmente, reduzir as taxas de cesarianas primárias ${ }^{27 .}$

Por outro lado, o parto normal pode ser considerado um procedimento de maior risco no que tange aos traumas físicos, tanto materno quanto fetal. Sempre houve discussão de que o parto, em especial o trauma de parto, é uma causa freqüente de paralisia cerebral no nascituro, tendo como consequiência a encefalopatia neonatal. Esta anomalia foi estabelecida em meados do século 19 , e segundo alguns estudos, permanece incontestada até os dias atuais ${ }^{28}$. A fisiopatologia é baseada na lesão hipóxico-isquêmica, resulta em disfunção de múltiplos órgãos e dano encefálico. A encefalopatia hipóxico-isquêmica constitui a consequência mais grave da asfixia perinatal, sendo causadora de sequelas neurológicas ${ }^{29}$.

Ocorre que uma pesquisa evidenciou que o aumento das taxas de cesariana não acompanhou a redução proporcional dos casos de paralisia cerebral nas crianças nascidas decorrentes do parto normal. Os autores fizeram uma revisão da literatura sobre a patogênese da encefalopatia neonatal e paralisia cerebral e suas relações com o período intraparto. Em 1998, o Western Australia Case-control Study demonstrou que muitos casos de encefalopatia neonatal 
não resultam em paralisia cerebral e que a incidência de encefalopatia neonatal atribuível a eventos intraparto, na ausência de qualquer outra anormalidade pré-concepcional ou anteparto, é estimada como sendo de aproximadamente 1,5 por 10.000 crianças $^{28}$.

Do mesmo modo, tem sido demonstrado que as causas de encefalopatia neonatal são heterogêneas e podem decorrer de outros fatores tanto pré-concepcionais como antenatais. Alguns estudos observaram que não há evidência de hipóxia intraparto em mais de $70 \%$ dos casos de encefalopatia neonatal e que a hipóxia intraparto isolada é responsável por somente $4 \%$ dos casos de encefalopatia grave dos recém-nascidos. Além disso, a hipóxia intraparto pode estar sobreposta a fatores de risco pré-concepcionais ou anteparto com dano pré-existente em $25 \%$ dos $\operatorname{casos}^{28-29-30}$. A Tabela abaixo demonstra alguns fatores de risco ligados à Encefalopatia ${ }^{28}$ :

Tabela 6: Fatores de risco para encefalopatia do recém-nascido

\begin{tabular}{|c|c|}
\hline Fatores de risco & OR ajustada (IC95\%) \\
\hline \multicolumn{2}{|l|}{ Pré-concepcionais } \\
\hline Tratamento para infertilidade & $4,43(1,12-17,60)$ \\
\hline História familiar de doença neurológica & $2,73(1,16-6,41)$ \\
\hline História familiar de convulsões & $2,55(1,31-4,04)$ \\
\hline \multicolumn{2}{|l|}{ Anteparto } \\
\hline CIUR*<percentil 3 & $38,23(9,44-154,79)$ \\
\hline CIUR* percentil 3-9 & $4,37(1,43-13,38)$ \\
\hline Doença tireoidiana materna & $9,7(1,97-47,91)$ \\
\hline Pré-eclâmpsia grave & $6,3(2,25-17,62)$ \\
\hline Hemorragia anteparto moderada a grave & $3,57(1,30-13,38)$ \\
\hline Doença viral & $2,97(1,52-5,80)$ \\
\hline Anormalidades morfológicas da placenta & $2,07(1,15-3,73)$ \\
\hline \multicolumn{2}{|l|}{ Intraparto } \\
\hline Evento intraparto agudo & $4,44(1,30-15,22)$ \\
\hline Apresentação occipto posterior & $4,29(1,79-10,54)$ \\
\hline Hipertermia intraparto & $3,86(1,44-10,12)$ \\
\hline Parto instrumentado & $2,34(1,16-4,70)$ \\
\hline Cesariana de emergência & $2,17(1,01-4,64)$ \\
\hline
\end{tabular}

* CIUR: crescimento intrauterino restrito

Fonte: Modificado de Badawi $\mathrm{N}$ et al, 1998.4.5

Portanto, as evidências atuais dão embasamento para o conceito de que a paralisia cerebral deve ser o resultado de uma combinação de fatores que vão desde uma predisposição genética e perpassam por fatores desencadeadores, os quais podem atuar tanto no ambiente intra como extrauterino. Os fatores de risco para encefalopatia do recém-nascido vem aumentando, à medida que o conhecimento médico se desenvolve de forma mais precisa ${ }^{28}$.

Em que pese por muito tempo, as causas freqüentes de paralisia cerebral na infância tenham sido relacionadas ao nascimento, particularmente no período intraparto, uma vez que as evidências científicas não dessem a sustentação necessária, as causas de paralisia cerebral na 
infância são múltiplas, frequentemente desconhecidas, podendo ter sua gênese durante os períodos pré-concepcional, pré-natal, intraparto ou após o nascimento. Em fetos previamente saudáveis, é provável que o trabalho de parto e o parto sejam responsáveis por menos de $5 \%$ dos casos de paralisia cerebral. Antes de culpar o parto ou seu atendimento, como causador de dano cerebral permanente, deve-se ser considerada a presença de critérios cientificamente aceitos que definam um evento hipóxico agudo intraparto como suficiente ou não para causar paralisia cerebral $^{28-30}$.

Uma revisão sistemática acerca do tema buscou nos bancos de dados SciELO, Bireme, Medline 26 artigos e três livros. As avaliações neurológicas neonatais auxiliam na detecção de anormalidades, possibilitando o tratamento precoce e otimização do prognóstico. Porém, são raros os estudos que utilizaram tais modalidades de avaliação nessa população. A fisiopatologia do insulto hipóxico-isquêmico é complexa. A forma como a mesma se desenvolve varia de acordo com a severidade, momento e duração do dano encefálico, além da idade gestacional. $\mathrm{O}$ evento hipóxico costuma ocorrer no período intra-uterino por causas maternas e fetais em $20 \%$ dos quadros, durante o trabalho de parto em $35 \%$ e ainda em $10 \%$ no período pós-natal ${ }^{29}$. Observou-se nesta pesquisa que a literatura que aborda conceitos teóricos da asfixia perinatal, como diagnóstico, fatores de risco e fisiopatologia é muito mais extensa que a quantidade de estudos que relatam suas conseqüências ${ }^{29}$.

Independentemente do tipo de parto realizado, o ponto forte deste trabalho é reconhecer a importância e conhecer os resultados e fatores relacionados à prática médica na obstetrícia, seja ela durante a realização do parto normal ou cesariana, sendo fundamental formular medidas, no sentido de fomentar e discutir as melhores práticas dos profissionais da saúde obstétrica, sobretudo, minimizar os riscos e proporcionar maior segurança à vida e saúde materna e fetal, já que o estudo utilizou de dados e informações concretas acerca das indenizações relacionadas ao parto realizado, que levam a contribuir e ampliar a possibilidade de comparações com resultados em nível nacional.

As limitações do trabalho referem-se ao desenho observacional, que inviabiliza a identificação ampla do pensamento do Judiciário Brasileiro acerca das indenizações em obstetrícia. Os resultados obtidos no estudo revelam tão somente o entendimento do Superior Tribunal de Justiça, cujo critério de seleção das decisões, limita a abrangência do número de casos disponíveis para análise, uma vez que as matérias submetidas aos Tribunais Superiores não podem revolver fatos e provas. Sem contar ainda, que a maioria das decisões transitam em julgado em primeira e segunda instâncias, não sendo submetidas, muitas vezes, ao reexame das instâncias superiores. 


\section{Conclusão}

O estudo demonstra a necessidade de identificação e implantação de intervenções efetivas na minimização dos riscos que geram os danos e sequelas no momento puerperal, assim como a redução da mortalidade materna durante o parto e a integridade à vida e saúde do nascituro. Tais medidas devem ser prioridades das instituições públicas, privadas e da própria sociedade.

Em que pese o entendimento do Superior Tribunal de Justiça reflita uma restrita parcela das ações objeto da pesquisa, as informações e dados levantados podem servir de parâmetro para os demais casos em instâncias inferiores, uma vez que esta Corte uniformiza e pacifica as questões relativas à lei federal. Dessa forma, os elementos disponíveis constantes das decisões em consonância com as práticas reconhecidamente úteis podem ser instrumentos hábeis a estimular desde o início da gestação as melhores evidências científicas a partir dos casos concretos, seja para possibilitar maior segurança à parturiente, seja para proteger a vida e integridade do feto.

\section{Referências}

1. World Health Organization (1996). Care in normal birth: A practical guide. Geneva, Switzerland: Author; Disponível

em: http://whqlibdoc.who.int/hq/1996/WHO_FRH_MSM_96.24.pdf.

2. Alencar Júnior CA. Os elevados índices de mortalidade materna no Brasil: razões para sua permanência. Rev Bras Ginecol Obstet. 2006;28(7):9-11. Disponível em: http://www.scielo.br/pdf/rbgo/v28n7/01.pdf.

3. Say L, Chou D, Gemmill A, Tunçalp Ö, Moller A-B, Daniels J, et al. Global causes of maternal death: a WHO systematic analysis. Lancet Glob Health. 2014;2(6):e323-33. Disponível em: http://www.thelancet.com/journals/langlo/article/PIIS2214109 X\%2814\%2970227-X/abstract.

4. Moura FMDJSP, Crizostomo CD, Nery IS, Mendonça RDCM, de Araújo OD, da Rocha SS. Humanization and nursing assistance to normal childbirth.. 2007;604. Rev Bras Enferm: 452-5. Disponível em: http://www.scielo.br/pdf/reben/v60n4/a18.pdf.

5. Brasil, ONU BR. Cai a mortalidade materna no mundo, aponta OMS; redução no Brasil chega a 43\%, 2014. Disponível em: http://www.onu.org.br/cai-a-mortalidade-materna-nomundo-aponta-oms-reducao-no-brasil-chega-a-43/. 
6. Brasil. Fiocruz. Nascer no Brasil. Pesquisa revela número excessivo de cesarianas, 2014. Disponível em http://portal.fiocruz.br/pt-br/content/pesquisa-revela-numero-excessivo-decesarianas-no-pais.

7. Luis P, Paula A, Pereira E, Orlando A, Schilithz C. Sampling design for the Birth in Brazil : National Survey into Labor and Birth. Desenho da amostra Nascer no Brasil, 2014. 1-10. Disponível em: http://www.scielo.br/pdf/csp/v30s1/0102-311X-csp-30-s1-0049.pdf.

8. Brasil. Portal Brasil. $5^{\circ}$ Relatório Nacional de Acompanhamento do ODM - Objetivos de Desenvolvimento do Milênio e a Construção da Agenda pós-2015. Disponível em: http://www.brasil.gov.br/governo/2014/05/5o-relatorio-nacional-de-acompanhamento-dosodm-sera-lancado-quarta-21.

9. ANS. Agência Nacional de Saúde publica resolução para estimular parto normal na saúde suplementar Detalhes Categoria: Consumidor. Art. $1^{\circ}$ da Resolução Normativa - RN No 368, de 6 de janeiro de 2015, 2015. Disponível em: http://www.ans.gov.br/aans/noticiasans/consumidor/2718-ministerio-da-saude-e-ans-publicam-resolucao-para-estimular-partonormal-na-saude-suplementar\#sthash.da35g6eA. 
10. Cavalcante SL, Friche AADL, Silva AAM Da, Campos D, Bittencourt SDDA, Carvalho ML De, et al. Pesquisa Nascer no Brasil: perfil da mortalidade neonatal e avaliação da assistência à gestante e ao recém-nascido. Cad Saude Publica, Rio Janeiro. 2014;30(sup):192-207. Disponível em: http://www.scielo.br/pdf/csp/v30s1/0102-311X-csp30-s1-0192.pdf.

11. Brasil. Ministério da Saúde. Secretaria de Políticos de Saúde. Área Técnica de Saúde da Mulher. Parto, aborto e puerpério: assistência humanizada à mulher/Ministério da Saúde, Secretaria de Políticas de Saúde, Área Técnica da Mulher - Brasília, 2001. Disponível em: http://bvsms.saude.gov.br/bvs/publicacoes/cd04_13.pdf.

12. Federação Brasileira das Associações de Ginecologia e Obstetrícia - FEBRASGO. Erro Médico no dia a dia da ginecologia e obstetrícia; [Internet]. 2014. [citado 20 set 2014]. Disponível em: http://www.febrasgo.org.br/site/?p=2019.

13. Brasil, Constituição Federal. Artigo $5^{\circ}$, caput "Todos são iguais perante a lei, sem distinção de qualquer natureza, garantindo-se aos brasileiros e aos estrangeiros residentes no País a inviolabilidade do direito à vida, à liberdade, à igualdade, à segurança e à propriedade, 1988. Disponível em: http://www.planalto.gov.br/ccivil_03/Constituicao/Constituicao.htm.

14. Nomura Seizo; Zugaib, Marcelo RMY; M. O perfil dos médicos denunciados que exercem ginecologia e obstetrícia no Estado de São Paulo. Rev Assoc Med Bras, 2006; 52:144-7. Disponível em: http://www.scielo.br/pdf/ramb/v52n3/a02v52n3.pdf.

15. Garfinkel A. responsabilidade civil por erro médico segundo a jurisprudência do tribunal de justiça do Estado de São Paulo. 2007; 037-058.

16. Spina VPL, Sá EC. Viviam Paula Lucianelli Spina, Eduardo Costa Sá. Perfil das demandas judiciais cíveis por erro médico em Ginecologia e Obstetrícia no Estado de São Paulo. 2015;20(1):15-20.

17. Mota, Aline Veras Leite. Análise do Discurso da Jurisprudência do STJ nas indenizações por erro médico: impacto no sistema de saúde. [dissertação de mestrado]. Ribeirão PretoFaculdade de Medicina de Ribeirão Preto - FMRP/USP, 2015. 
18. Kallas Filho, Elias. O fato da técnica: excludente da responsabilidade civil do médico. R. Dir. sanit, Brasil, v. 14, n. 2, p. 137-151; 2013. ISSN 2316-9044. Disponível em: http://www.revistas.usp.br/rdisan/article/view/63998>.

19. Conselho Federal de Medicina. Resolução CFM No 1931, de 17 de setembro de 2009. Art. 29 do Código de Ética Médica. Publicada no D.O.U. de 24 de setembro de 2009, Seção I, p. 90 , 2010. Disponível em: http://portal.cfm.org.br/index.php?option=com_content\&view=article\&id=20670:resolucaocfm-no-19312009-\&catid=9: codigo-de-etica-medica-atual\&Itemid=122.

20. Ulguim Oliveira, Daniele. A responsabilidade civil por erro médico. Âmbito Jurídico, Rio Grande, XI, n. 59; 2008. Disponível em: http://www.ambitojuridico.com.br/site/?n_link=revista_artigos_leitura\&artigo_id=3580>.

21. Yin, Robert K. Estudo de caso: planejamento e métodos / Robert K. Yin; tradução: Christian Matheus Herrera - 5. Ed. Porto Alegre: Bookman; 2015, p. 1-60.

22. Maximiliano, Carlos. Hermenêutica e aplicação do Direito. 20. ed. Rio de Janeiro: Forense, 2011, p. 146

23. Gabardo E, Tadeu F, Morettini R. Institucionalismo E Pesquisa Quantitativa Como Metodologia De Institutionalism and Quantitative Research As a Methodology for the Analysis of Judicial Decisions, 2010. 2013;151-80. Disponivel em: http://www.egov.ufsc.br/portal/sites/default/files/institucionalismo_e_pesquisa_quantitativa _como_metodologia_de_analise_de_decisoes_judiciais.pdf.

24. Seawright J, Gerring J. Case Selection Techniques in Case Study Research: A Menu of Qualitative and Quantitative Options. 2010. Polit Res Q. 2010. 2008; 61(2):294-308.. Disponível em: http://blogs.bu.edu/jgerring/files/2013/06/CaseSelection.pdf.

25. Coacci T. A Pesquisa com Acórdãos nas Ciências Sociais: Algumas Reflexões Metodológicas. Mediações - Rev Ciências Sociais. 2013;18(2):86. Disponível em: http://www.uel.br/revistas/uel/index.php/mediacoes/article/view/17313. 
26. Mota, Aline Veras Leite. Análise do Discurso da Jurisprudência do STJ nas indenizações por erro médico: impacto no sistema de saúde. [dissertação de mestrado]. Ribeirão PretoFaculdade de Medicina de Ribeirão Preto - FMRP/USP, 2015.

27. Kornacka MK, Kufel K. Neonatal outcome after cesarean section. Ginekol Pol. 2011 Aug;82(8):612-7. Review. Polish. PubMed PMID: 21957607.

28. Cox KJ, King TL. Preventing primary cesarean births: midwifery care. Clin Obstet Gynecol. 2015 Jun;58(2):282-93. doi: 10.1097/GRF.0000000000000108. Review. PubMed PMID: 25811129.

29. Martins-Costa S, Martins-Costa G, Ramos JGL. Parto, encefalopatia neonatal e paralisia cerebral. Femina. Abril 2009. vol 37 no 4, p. 223-227.

30. Cruz ACS, Ceccon MEJ. Prevalência de asfixia perinatal e encefalopatia hipóxicoisquêmica em recém-nascidos de termo considerando dois critérios diagnósticos. Rev Bras Crescimento Desenvolv Hum, 2010;20:302-16.

31. Takazono PS, Golin MO. Asfixia perinatal: Repercussões neurológicas e detecção precoce. Neurociencias. 2013;21(1):108-17. 


\section{Artigo 2}

Análise do discurso do STJ acerca das indenizações que envolvem parto natural e cesariana. STJ discourse analysis about the claims involving natural birth and caesarean

\section{Resumo}

Introdução: O Ministério da Saúde tem apostado na mudança da cultura do parto, a fim de estabelecer diretrizes que alcancem a sua assistência humanizada, aliada ao atendimento integral à gestante e à criança. Os profissionais da saúde, em especial, os médicos obstetras têm o papel relevante nesse processo, uma vez que participam de maneira ativa na aplicação do conhecimento e das melhores técnicas para realização de um parto seguro. Objetivo: Analisar o discurso dos julgadores do Superior Tribunal de Justiça (STJ), no tocante às intercorrências ocorridas durante o parto natural ou a cesariana. Método: Foi utilizada a Análise do Discurso do Sujeito Coletivo (DSC) das decisões, vez que o entendimento dos julgadores do STJ reflete opiniões, posicionamentos acerca das indenizações que envolvem o parto normal e a cesariana. Resultados: Foram identificadas no discurso dos Julgadores do STJ as correntes majoritárias que pacificam o entendimento de determinadas questões que envolvem as demandas judiciais relacionadas aos procedimentos estudados. O posicionamento dos julgadores acerca da responsabilidade objetiva dos hospitais, sejam públicos ou privados, foi unânime, ao passo que aos médicos foi atribuída a responsabilidade subjetiva, devendo ser comprovada a culpa do profissional. Quando comprovada a culpa do médico obstetra, ele se torna responsável solidário com o hospital. É entendimento majoritário do STJ a caracterização da relação médico-mãe-feto, como relação de consumo, cujas normas estão previstas no Código de Defesa do Consumidor. As provas periciais produzidas foram essenciais para o desfecho da ação. Segundo o posicionamento dos julgadores, as más práticas decorreram da negligência dos profissionais. As ações improcedentes sustentaram que a obrigação de meio excluiu a responsabilidade, desde que realizados todos os procedimentos necessários e adequados, cujo resultado, ainda que não esperado, não revela desacerto profissional. A União foi excluída em todas as demandas, sendo unânime o entendimento acerca de sua iletigimidade para responder eventuais danos relacionados ao Sistema Único de Saúde. Conclusão: Tendo em vista a prevalência das demandas judiciais na obstetrícia, especialmente às relacionadas ao parto, a análise do discurso coletivo dos julgadores do STJ revela as discussões dos casos concretos em última instância, sendo importante identificar o predomínio das correntes jurisprudenciais da Corte, a fim de obter subsídios para as organizações de saúde, sobretudo minimizar o ativismo judicial e os riscos decorrentes da máprática médica obstétrica, reduzir custos provenientes das altas indenizações e incentivar a humanização, a qualidade e excelência na assistência ao parto.

Palavras - Chaves: Jurisprudência, Obstetrícia, Parto Normal, Cesariana. 


\begin{abstract}
Introduction: The Brazilian Ministry of Health has invested in order to establish guidelines to achieve the humanized delivery and comprehensive care to pregnant women and children. Obstetrician physicians have the key role in this process, as participating actively in the application of knowledge, technique and method. Objective: It was to identify the decisions of the High Court of Justice (STJ), which type of delivery: natural or cesarean the chance of complications are most frequent, the judgments of valuation and the profile of the judges at the damage and consequences arising from childbirth and postpartum. Method: It was used the method of Collective Subject Discourse Analysis of the decisions, since the understanding of the judges of the Superior Court of Justice, reflects opinions, positions about claims involving vaginal Results: Speaking of STJ judges identified the majority currents that pacify the understanding of certain matters involving claims related to vaginal delivery and cesarean section. The positioning of the judges on the strict liability of hospitals, whether public or private was unanimous, while the doctors was attributed to subjective responsibility and must be proven professional's fault. When proven the guilt of the obstetrician, he becomes jointly liable with the hospital. It is prevailing understanding of the STJ characterization of doctor-mother-child relationship, as the consumption process, whose rules are set out in the Consumer Protection Code. The expert evidence produced were essential to the outcome of the action. According to the position of judges, bad practices resulted from the negligence of professionals. The unfounded actions maintained that the obligation of means excluded the responsibility, since performed all necessary and appropriate procedures, the result of which, although not expected, does not reveal professional mistake. The Union was excluded in all demands, and unanimous understanding about their exclusion to answer any damage related to the Unified Health System. Conclusion: Given the prevalence of litigation in obstetric medical field, especially at childbirth related practices, the analysis of the collective discourse of the STJ judges reveal the discussions of individual cases ultimately being important to identify the predominance of jurisprudential currents of the Court in order to obtain subsidies for health organizations, especially minimize judicial activism and the risks obstetric medical malpractice, reduce costs from the high indemnities and encourage the humanization, quality and excellence in delivery care.
\end{abstract}

Key Words: Jurisprudence, Obstetrics, Childbirth Natural, Cesarean Section, 


\section{Introdução}

O Brasil possui uma das maiores taxas de cesarianas do mundo. Segundo os dados do Datasus, a última pesquisa revelou que em 2013 foram realizados 621.216 partos naturais e 792.490 cesarianas $^{1}$. As recomendações da Organização Mundial da Saúde são para que apenas de $10 \%$ a $15 \%$ dos partos sejam realizados por meio deste procedimento cirúrgico ${ }^{2}$. Alguns fatores contribuíram para este resultado, tais como a evolução das técnicas cirúrgicas e anestésicas, os riscos reduzidos de complicações pós-operatórias imediatas, a prática obstétrica defensiva, as características do sistema de saúde e consequente remuneração, além da própria demanda das pacientes ${ }^{3}$.

Em que pese o resultado demonstrar um notável progresso na assistência obstétrica, uma vez que várias razões médicas são aceitáveis, tendo em vista o melhor prognóstico materno e perinatal, existem argumentos contra a realização excessiva da cesariana. Alguns dados apontam que, aproximadamente, 850.000 cesarianas desnecessárias são realizadas a cada ano na América Latina ${ }^{4}$. Estudos afirmam que a cesárea deveria ser evitada, uma vez que aumenta os riscos reprodutivos, sem prejuízo do desenvolvimento local, da capacitação do sistema de saúde, do tipo de paciente assistida e do nível de complexidade hospitalar. O procedimento é associado a alguns eventos adversos, tais como, maior necessidade de antibióticos após o parto; maior morbidade e mortalidade materna; aproximadamente, quatro a cinco vezes maiores que o parto natural; prematuridade; permanência em unidade de terapia intensiva (UTI) e morte neonatal. Por isso, a decisão tomada para realização de uma cesariana deve ser criteriosa e discutida com a paciente ${ }^{2,3,5,6}$.

Dessa forma, muito tem se discutido acerca do parto humanizado como um conjunto de propostas de mudança nas práticas obstétricas, a fim de levar aos serviços relacionados ao parto, conceitos novos e desafiadores e às vezes conflitantes, pois busca-se maior humanização na assistência à parturiente e à criança que está sendo gerada. As abordagens baseadas em evidências científicas e as baseadas em direitos estão sendo recriadas e utilizadas como instrumentos para a mudança de cultura do parto ${ }^{7}$.

Existem várias práticas realizadas pelos médicos obstetras necessárias desde o pré-natal até o primeiro período do trabalho de parto. Não há evidências contra ou a favor do parto domiciliar ou em hospitais, porém estudos sugerem uma menor frequência de intervenções médicas no parto domiciliar. Destaca-se que no hospital, o parto na sala de PPP (pré-parto, parto e pós-parto) do centro obstétrico, associa-se também a menores intervenções médicas e maior satisfação materna $^{7,8}$.

Uma revisão da literatura foi realizada na busca das melhores evidências disponíveis sobre a assistência ao primeiro período do trabalho de parto de forma mais humanizada. Foi abordado 
desde o local da assistência, a importância da definição do risco da gestante, até a posição da paciente e algumas intervenções, tais como, jejum, realização de enema, punção venosa e infusão de líquidos, tricotomia, deambulação, utilização do partograma, monitorização da frequência cardíaca fetal, manejo ativo do trabalho de parto com utilização de ocitocina e amniotomia precoce, o alívio da dor por métodos não farmacológicos, a analgesia de parto peridural e combinada, além do suporte contínuo intraparto ${ }^{8}$. Neste estudo, constatou-se que procedimentos como jejum, tricotomia e enteróclise devem ser evitados, uma vez que não há evidências para sua utilização. Parturientes devem ser encorajadas a deambular ou adotar a posição que preferirem durante o primeiro período do parto. Imersão em água e suporte contínuo intraparto reduzem efetivamente a dor no momento do parto. Hipnose e acupuntura são métodos não farmacológicos para alívio da dor que levam à redução significativa da necessidade de analgesia. A pesquisa ainda revelou que o uso do partograma em países de baixa renda se associa à redução das taxas de cesariana, assim como o manejo ativo do trabalho de parto com amniotomia e ocitocina não deve ser recomendado de rotina ${ }^{8}$.

Todavia, todas as decisões sobre assistência ao primeiro período de parto devem ser discutidas previamente com as parturientes, sobretudo em situações em que não existem evidências suficientes para sua recomendação9 .

Destarte, uma recente revisão sistemática demonstrou que a cesariana planejada em comparação com o parto vaginal, reduziu a morte perinatal ou neonatal, bem como a morbidade neonatal grave, contudo revelou o aumento da morbidade materna ${ }^{10,11}$.

Outra pesquisa analisou a morbidade neonatal e materna e a mortalidade neonatal de acordo com o tipo de parto, cesariana ou vaginal. Foram estudadas prospectivamente 170 parturientes sem complicações gestacionais e com nascimento a termo: Grupo $1(\mathrm{n}=95)$, puérpera com parto por via vaginal, Grupo $2(\mathrm{n}=75)$, puérpera submetida à cesariana. Foi observada maior incidência de partos por via vaginal nas pacientes que estudaram até o ensino fundamental incompleto. Observou a preferência de $78(82,1 \%)$ das mulheres do Grupo 1 pelo parto vaginal contra apenas $28(37,3 \%)$ das mulheres do Grupo 2, pela cesariana. Houve dor intensa no pós-operatório nas pacientes submetidas a parto cesáreo (oito casos). Traumas obstétricos foram verificados em catorze recém-nascidos do Grupo 1 e em sete do Grupo 2. Foi concluído que existe maior morbidade neonatal em recém-natos de parto por via vaginal quando comparada com neonatos de cesariana, bem como, maior morbidade materna em puérperas submetidas à cesariana ${ }^{12}$.

Um estudo comparou resultados com base nos dois anos após cesariana planejada e parto vaginal. Nos casos selecionados, as mães responderam a um questionário estruturado, retratando sua saúde nos últimos três a seis meses. Um total de 917 (79,1\%) em 1.159 mães de 85 centros, 
relataram que não houve diferenças entre os grupos em amamentação, relação com a criança ou parceiro, dor, gravidez subseqüente, incontinência urinária, depressão, problemas menstruais ou sexuais, fadiga ou memórias angustiantes com a experiência do nascimento. A única diferença significativa foi um aumento de constipação nas pacientes que realizaram cesariana. Em contrapartida, os recém-nascidos não foram protegidos da morte ou do dano cerebral por terem nascido de cesariana eletiva ${ }^{13}$.

Dessa forma, as pesquisas buscam as melhores evidências disponíveis sobre indicações de cesariana, tais como placenta prévia, descolamento prematuro de placenta, placenta acreta, infecção por HIV, herpes genital, hepatites, HPV, condiloma genital, gestação múltipla, prolapso do cordão umbilical, distensão segmentar e ruptura uterina. Observou-se que a cesariana está formalmente indicada em algumas situações particulares, como na placenta prévia total. Em outros casos, pode haver indicação de cesariana intraparto, porém situações como HPV e gemelaridade não representam indicações para a realização do procedimento ${ }^{3,14}$.

Todas as mulheres em trabalho de parto devem ser avaliadas pelo médico, sendo que os eventuais riscos merecem ser expostos, uma vez que o manejo e o local do parto variam em função deste risco. A avaliação deve ser realizada inicialmente e durante todo o trabalho de parto. Pesquisas apontam que são várias as situações de riscos, dentre elas: (a) padrões anômalos de frequência cardíaca fetal; (b) falha de progressão; (d) sangramento; (e) apresentação pélvica; (f) parto disfuncional; (g) malformação cardíaca congênita; (h) outras malformações fetais reconhecidas; (i) restrição de crescimento intrauterino; (j) cardiopatia materna; (k) diabetes materno (clínico ou gestacional); (l) hipertensão materna; (m) lupus e outras colagenoses; (n) gestação múltipla; (o) oligohidrâmnio; (p) outras condições médicas crônicas ou agudas maternas e/ou fetais; (q) uso de ocitocina; (r) gestação prolongada (maior ou igual que 42 semanas); (s) mecônio espesso ${ }^{8}$.

A tomada de decisões baseadas nas melhores evidências é sempre a forma mais segura para o profissional da saúde e a paciente. Segundo alguns especialistas, a relação médico-paciente não deve ser vista como uma relação de consumo, sob a tutela do Código do Consumidor, uma vez que o resultado do trabalho do obstetra não pode ser equiparado à garantia de um bem de consumo ${ }^{15}$. Contudo, alguns estudos e até mesmo a jurisprudência dominante apontam que a relação médica é uma relação consumerista, pois, como fornecedor de serviços, independentemente da existência de culpa, há a responsabilidade pela reparação dos danos causados aos "consumidores" pelos defeitos relativos à má prestação de serviços 15-17.

Independentemente de qualquer situação de risco ou não, a boa relação médico-paciente deve pautar-se pela transparência e confiança. Entre diferentes medidas recomendadas ao médico, há necessidade de permanente capacitação e atualização, o uso adequado de tecnologias e os 
tratamentos propostos que tenham indicações precisas ${ }^{15,16}$. Nessa linha, algumas pesquisas sugerem que os obstetras têm decidido suas intervenções sob a ótica do menor risco para si. Esta mudança de atitude tem sido justificada pelos inúmeros processos judiciais contra os profissionais de saúde, acarretando enorme custo emocional, psicológico e econômico para quem pratica obstetrícia ${ }^{15,17}$.

As denúncias relacionadas à prática médica obstétrica e ginecológica apresentadas no Conselho Federal de Medicina são frequentes, sendo quase 30\% do total de queixas, segundo a Federação Brasileira das Associações de Ginecologia e Obstetrícia - FEBRASGO ${ }^{18}$, ainda porque, a obstetrícia é a especialidade de maior risco judicial dentro da prática médica, face ao grande número de intercorrências no período de pré-natal e nas urgências e emergências no trabalho de parto ${ }^{19}$.

Nesse contexto, o presente trabalho identificou no discurso dos julgadores do STJ a discussão dos conflitos que envolvem a seara da responsabilidade civil do médico obstetra frente às inúmeras intercorrências que ocorrem durante as tomadas de decisões, especialmente àquelas diretamente ligadas ao parto e puerpério.

As decisões apreciadas e julgadas pelo STJ nos anos de 2004 a 2014 foram selecionadas, com o objetivo de serem extraídos os principais posicionamentos dos Ministros da Corte, no tocante à responsabilidade objetiva do Hospital; a responsabilidade subjetiva do médico; a responsabilidade solidária do médico e hospital; as possíveis falhas na prestação de serviços, com base na relação de consumo; as provas produzidas e o convencimento dos Julgadores; as possíveis más práticas dos procedimentos (cesariana e parto natural), assim como o fato da técnica, dano, culpa e nexo causal.

\section{Método}

A pesquisa utilizou o método de análise do Discurso do Sujeito Coletivo (DSC) de Lefévre, com base, sobretudo nos pressupostos da "Teoria das Representações Sociais". A teoria elenca uma série de operações sobre a matéria-prima de depoimentos coletados em pesquisas empíricas de opinião, operações que redundam, ao final do processo, em depoimentos coletivos confeccionados com extratos de diferentes depoimentos individuais - cada um desses depoimentos coletivos veiculando uma determinada e distinta opinião ou posicionamento, redigidos na primeira pessoa do singular, com vistas a produzir, no receptor, o efeito de uma opinião coletiva, expressando-se, diretamente, como fato empírico, por meio do sujeito coletivo que "fala" ${ }^{20}$. Esta técnica consiste em selecionar, cada discurso individual a uma questão, as expressões-chaves, que são trechos mais significativos destas respostas. As "expressões-chaves" correspondem as "ideias centrais" que são a síntese do conteúdo discursivo manifestado, que constroem-se discursos-síntese, na primeira pessoa do singular ${ }^{21}$. 
Optou-se pelo discurso dos Julgadores do Superior Tribunal de Justiça em razão desta Corte resolver, respectivamente, questões diretamente relacionadas com as normas federais em última instância, e uniformizarem o entendimento a respeito da matéria foco principal da pesquisa em caráter nacional, servindo de parâmetro para a resolução das demandas judiciais pelos juízes de primeira e segunda instância.

Ocorreram duas etapas de busca das decisões que abrangem o tema. Primeiramente, a seleção dos acórdãos foi realizada em um trabalho acadêmico ${ }^{22}$, cujos resultados apontaram um universo de 90 (noventa) julgados extraídos do site do STJ num período de 2003 a 2013, que debatem sobre erros médicos, sendo 12 (doze) deles, referente às práticas danosas na obstetrícia. O levantamento dos julgados foi realizado no campo "pesquisa livre", utilizando os seguintes termos: "erro médico"; "médico"; "paciente"; "profissional da saúde"; "dano moral"; "dano material"; "SUS"; "responsabilidade civil" e "indenização por erro médico", escolheu-se a classe "Recurso Especial" que foram admitidos e julgados pelo STJ.

Num segundo momento, foi realizada uma nova pesquisa, com o objetivo de abranger os casos julgados pelo STJ no período de 2004 a 2014. A busca foi realizada no campo "pesquisa livre" com os seguintes termos: "erro médico" e "parto". O resultado da pesquisa encontrou 13 (treze) decisões em "Recurso Especial" e em "Agravo Regimental no Agravo em Recurso Especial" que foram apreciadas pelo STJ, dos quais quatro deles constavam na primeira seleção das decisões, o que resultou num total de 21 (vinte e um) julgados.

Após a análise objetiva dos fatos e dados de cada caso, foram analisados os objetos de investigação, sendo possível identificar os fundamentos utilizados pelos julgadores, o entendimento externado acerca da matéria debatida, a fim de tornar possível a identificação de correntes de jurisprudência e a formação do perfil dos julgadores do STJ.

\section{Aspectos Éticos}

Ficou dispensada a aplicação do Termo de Consentimento Livre e Esclarecido, uma vez que o trabalho não envolve pesquisa com seres humanos, apenas descrição e análise do discurso dos julgadores do STJ, sendo os dados públicos, extraídos do site do Poder Judiciário.

\section{Resultados}

O trabalho revelou que a maioria das supostas falhas médicas obstétricas que originaram as ações indenizatórias, ocorreu durante a realização do parto normal, ou seja, 71\%, dos casos, comparado à cesariana com $29 \%$. As tabelas abaixo demonstram os danos e sequelas causados durante a realização de cada tipo de parto e o tipo de hospital, se público ou privado.

Na Tabela 3, se observam os dados relacionados à cesariana. 
Tabela 3 - Associação do parto cesárea, às causas dos danos, às sequelas sofridas e tipo de hospital, se público ou privado.

\begin{tabular}{|c|c|c|c|c|}
\hline $\begin{array}{l}\text { Tipo de } \\
\text { Parto }\end{array}$ & Caso & Causas dos Danos & Danos & Hospital \\
\hline \multirow{6}{*}{ Cesárea } & 1 & $\begin{array}{l}\text { Esquecimento de compressa } \\
\text { cirúrgica no organismo da } \\
\text { parturiente }\end{array}$ & $\begin{array}{l}\text { Mãe sofreu retirada da trompa esquerda; transfusão de } \\
\text { sangue; drenagem }\end{array}$ & Privado \\
\hline & 2 & Prescrição irregular de medicação & Perda do filho e extração do utero da mãe & Privado \\
\hline & 3 & $\begin{array}{c}\text { Demora na realização do parto - } \\
\text { Sofrimento fetal }\end{array}$ & $\begin{array}{l}\text { Nascituro sofreu paralisia cerebral tipo hemiparesia à } \\
\text { esquerda }\end{array}$ & Público \\
\hline & 4 & $\begin{array}{l}\text { Esquecimento de compressa } \\
\text { cirúrgica no organismo da } \\
\text { parturiente }\end{array}$ & $\begin{array}{l}\text { Mãe sofreu septicemia; retirada parcial do útero; } \\
\text { utilizou bolsa de colostomia; perda auditiva e cicatrizes }\end{array}$ & Público \\
\hline & 5 & $\begin{array}{l}\text { Falta de material adequado para } \\
\text { procedimento cirúrgico }\end{array}$ & Nascituro sofreu asfixia hipóxico-isquêmica & Público \\
\hline & 6 & Complicações anestésico-cirúrgicas & $\begin{array}{c}\text { Mãe sofreu parada cardiorrespiratória e coma } \\
\text { irreversível durante o parto }\end{array}$ & Público \\
\hline
\end{tabular}

A cesariana foi realizada em seis casos estudados, sendo dois deles decorrentes do esquecimento de material cirúrgico durante o procedimento. No primeiro caso, os autos retornaram à origem, uma vez que foi reaberta a oportunidade do hospital para comprovar a culpa exclusiva de terceiro (médico). No caso 4, a ação foi julgada procedente em virtude dos danos físicos, estéticos, morais e materiais (incapacidade funcional parcial) causados à parturiente. Neste caso indenizações somaram R \$ 1.275.000,00. Ainda, em decorrência da prescrição irregular de medicação (caso2) e das complicações anestésico-cirúrgicas, as sequelas causadas à mãe foram irreversívies: perda do útero e coma irreversível.

No caso decorrente das complicações anestésico-cirúrgicas, restou evidenciada a negligência do hospital (caso 6) em não disponibilizar um profissional experiente e capacitado para acompanhar a médica residente, cursando o primeiro ano de residência, na realização de um procedimento complexo como a referida cirurgia. Concluiu-se pelo laudo pericial que a presença de um anestesista mais experiente talvez evitasse os problemas ocasionados à vítima, contando com todo aparato de monitoração e identificar a iminência de uma parada cardiáca, tomando as medidas necessárias para prevení-la.

A tabela seguinte demonstra que a principal causa dos danos ligados ao parto normal, relatados nos acórdãos foi a demora na realização do parto, sendo apurado este fato em sete decisões, com os traumatismos em segundo lugar. As sequelas irreversíveis ocorridas nos recémnascidos predominam como os danos mais recorrentes, à frente dos óbitos fetais e dos danos irreversíveis sofridos pela mãe. 
Tabela 4 - Associação do parto normal às causas dos danos, às sequelas sofridas e tipo de hospital, se público ou privado.

\begin{tabular}{|c|c|c|c|c|}
\hline $\begin{array}{l}\text { Tipo de } \\
\text { Parto }\end{array}$ & Caso & Causas dos danos & Danos & Hospital \\
\hline & 7 & Demora na realização do parto & $\begin{array}{c}\text { Nascituro sofreu sequelas neurológicas } \\
\text { irreversíveis }\end{array}$ & Público \\
\hline & 8 & Conduta culposa do médico & Óbito fetal & Público \\
\hline & 9 & Traumatismo & Nascituro sofreu paralisia cerebral & Privado \\
\hline & 10 & $\begin{array}{l}\text { Ausência de assistência do médico obstetra. } \\
\text { Posição incomum do feto }\end{array}$ & Sequelas motoras irreversíveis & Privado \\
\hline & 11 & Demora na realização do parto & $\begin{array}{c}\text { Nascituro sofreu sequelas irreversíveis - } \\
\text { paraplegia }\end{array}$ & Privado \\
\hline & 12 & Período expulsivo prologado do feto & $\begin{array}{c}\text { Nascituro sofreu lesões corporais e } \\
\text { neurológicas }\end{array}$ & Privado \\
\hline & 13 & Anoxia decorrente de Tocotraumatismo & $\begin{array}{c}\text { Nascituro sofreu sequelas neurológicas } \\
\text { irreversíveis }\end{array}$ & - \\
\hline \multirow[t]{8}{*}{$\begin{array}{c}\text { Parto } \\
\text { Normal }\end{array}$} & 14 & Demora na realização do parto & Nascituro sofreu sequelas irreversíveis & Privado \\
\hline & 15 & Ausência de pediatra no parto & $\begin{array}{c}\text { Nascituro sofreu sequelas neurológicas } \\
\text { irreversíveis }\end{array}$ & Público \\
\hline & 16 & Asfixia fetal no parto & Encefalopatia hipóxico isquêmico neonatal & Privado \\
\hline & 17 & Parto normal - Posição inadequada do feto & $\begin{array}{c}\text { Nascituro sofreu sequelas neurológicas e } \\
\text { motoras }\end{array}$ & Público \\
\hline & 18 & Atendimento inadequado pós-parto & Nascituro sofreu distócia no ombro e asfixia & _ \\
\hline & 19 & Traumatismo & Nascituro sofreu sequela motora irreversível & Privado \\
\hline & 20 & $\begin{array}{c}\text { Choque Anafilático parturiente - Medicação } \\
\text { irregular }\end{array}$ & $\begin{array}{l}\text { Nascituro sofreu sequelas neurológicas no } \\
\text { feto - Mãe sofreu remoção do útero }\end{array}$ & Público \\
\hline & 21 & Demora na realização do parto & Óbito fetal & Privado \\
\hline
\end{tabular}

Fonte: Autora

Sob o prisma da análise qualitativa das decisões, foram selecionados os debates centrais. As discussões abordadas nos discursos dos julgadores permeiam a seara da responsabilidade civil dos profissionais de saúde da área obstétrica, assim como as intercorrências ocorridas durante o pré-parto, o parto e pós parto imediato, revelando como é a relação médico-mãe-feto, sob a ótica dos julgadores do STJ. 
Os temas centrais extraídos dos discursos foram subdivididos em temas da fala de cada julgador, conforme as questões tratadas nas decisões, que foram objeto para construção do DSC, demonstrando o entendimento prevalente da jurisprudência acerca das expressões-chaves e as ideias centrais.

Foram selecionadas as seguintes questões, objetos de discurso pelos julgadores:

- A - Responsabilidade objetiva do Hospital;

- B - Responsabilidade subjetiva do médico;

- C - Responsabilidade solidária do médico e hospital;

- D - Falha na prestação de serviços - Relação de Consumo;

- E - Provas produzidas;

- F - Má prática dos procedimentos do parto cesáreo e natural;

- G - Fato da técnica;

- H - Ilegitimidade passiva da União.

Dessa forma, a seguir apresentam-se as discussões predominantes, extraídas das expressões-chaves e as ideias centrais identificadas:

- DSC A - Discurso do Sujeito Coletivo acerca da responsabilidade objetiva do hospital

[...] Enquanto a responsabilidade do médico é subjetiva, a do hospital é objetiva. (art. 14 e $\S \S$ da lei 8078/90). Na prestação de serviço hospitalar, inverte-se o ônus da prova, visto que a hipótese encaixa-se perfeitamente nos ditames dos arts. $2^{o}$ e $3^{\circ}, \xi 2^{o}$, do Código de Defesa do Consumidor, uma vez que o hospital caracteriza-se como autêntico prestador de serviços, quando deverá sua responsabilidade ser decidida sob o abrigo da responsabilidade civil objetiva, como dispõe o art. 14, do mesmo diploma legal, cabendo ao mesmo demonstrar que inexistiu defeito e que a culpa pela infecção hospitalar foi do paciente ou terceiro [...].

[...]A prestação de serviço hospitalar está tipificada nas disposições dos arts. $2^{\circ}$ e $3^{o}, \S 2^{o}$, do CDC, razão por que a sua responsabilidade é objetiva, nos termos do art. 14 do CDC [...]. 
[...] Cerceamento de defesa. Necessidade de prova pericial para que o hospital possa demonstrar que não houve responsabilidade da sua equipe auxiliar nem dos seus equipamentos, sendo ela, integralmente, da própria médica que realizou a cirurgia e esqueceu o corpo estranho no organismo da paciente. O hospital recorre para provar que houve culpa exclusiva de terceiro, no caso a cirurgiã, o que é excludente de responsabilidade, nos termos do artigo $14, \S 3^{\circ}$, II do CDC [...].

\section{Comentários}

Para configuração da responsabilidade subjetiva do médico ou hospital, há necessidade da existência do dano, do nexo de causalidade e da culpa ou dolo. Isso significa que todos estes requisitos (dano, nexo causal, culpa/dolo) devem ser comprovados. Ressalta-se que a culpa se caracteriza pela conduta negligente, imprudente e imperita do agente causador do dano.

Para ser caracterizada a responsabilidade objetiva, ao contrário, independe de culpa do agente causador do dano. Isso porque, muito se discute se esta relação pode ser considerada como uma relação de consumo. O hospital é um fornecedor de serviços, equipamentos e medicamentos ao consumidor, mediante remuneração, nos termos do artigo $14^{23}$, caput do CDC, o que impõe ao prestador o dever de responder "independentemente de culpa", pelas reparações dos danos causados aos consumidores por defeitos relativos à prestação dos serviços, fornecimento de pessoal, material e equipamentos.

Ainda com base no disposto do artigo $37^{24}$, $\$ 6$, da Constituição Federal, a responsabilidade do hospital é objetiva, independendo de atuar culposo ou doloso o respectivo preposto.

\section{- DSC B - Discurso do Sujeito Coletivo acerca da responsabilidade subjetiva do médico}

[...] A relação entre paciente e médico-hospital é de contrato de prestação de serviços entre as partes. Assim, a vítima e o autor do dano estão vinculados por uma relação jurídica preexistente. Quem se compromete a prestar assistência médica por meio de profissionais que indica, é responsável pelos serviços que estes prestam, respondendo, pois, de forma objetiva (art. 14, caput, CDC). Por outro lado, a responsabilidade pessoal do médico pela prestação de serviços deve ser apurada mediante culpa por força do art. 14, $\S 4^{\circ}$, do CDC [...]. 
[...] A conduta negligente do profissional que ocasionar lesão ao paciente acarreta-lhe a obrigação de reparação dos danos. A instituição hospitalar, por sua vez, responde em decorrência do serviço prestado de forma irregular $[\ldots]$

[...] Na hipótese de prestação de serviços médicos, o ajuste contratual vínculo estabelecido entre médico e paciente - refere-se ao emprego da melhor técnica e diligência, entre as possibilidades de que dispõe o profissional no seu meio de atuação, em auxílio do paciente. Não se pode olvidar que, mesmo que os profissionais envolvidos empreguem toda sua diligência no ato, ainda assim podem advir reações imprevisíveis e situações inesperadas. Não podendo o médico assumir o compromisso com um resultado específico (exceto quando se tratar de cirurgia estética), outra não pode ser a teoria da responsabilidade que não a subjetiva, devendo-se averiguar se houve culpa do profissional [...].

\section{Comentários}

A conduta negligente do profissional que ocasionar lesão ao paciente acarreta-lhe a obrigação de reparação dos danos. A instituição hospitalar, por sua vez, responde em decorrência do serviço prestado de forma irregular.

A responsabilidade do médico é tida como subjetiva, pois só responde quando ele der causa ao dano agindo com imprudência, negligência ou imperícia. Age o médico com imprudência quando pratica o ato sem o necessário cuidado. Com negligência quando se omite quando deveria agir. E imperícia quando o faz sem o necessário conhecimento que deveria ter.

\section{- DSC C - Discurso do Sujeito Coletivo acerca da responsabilidade solidária do médico e do hospital}

[...] Restado comprovado que o médico, primeiro réu, foi negligente ao avaliar a mãe do autor, o que fez com que ele/autor nascesse com sequelas de natureza definitiva, deve ele (médico) ser condenado, solidariamente com o hospital, a pagar indenização, pelos danos morais causados [...]. 
[...] O sistema processual civil abraça o princípio do livre convencimento motivado, que, inclusive está positivado no artigo 131 do Código de Processo Civil, impondo ao julgador a indicação dos motivos de suas conclusões. Na hipótese em que a ação proposta tem sustentação na existência de erro médico, uma vez que realizada perícia, deve o julgador indicar os motivos pelos quais resolve concluir pela obrigação de indenizar, tomando posição oposta às conclusões do perito, mormente quando outras provas não existem nos autos. A responsabilidade do médico pressupõe o estabelecimento do nexo causal entre causa e efeito da alegada falta médica, tendo em vista que, embora se trate de responsabilidade contratual - cuja obrigação gerada é de meio - é subjetiva, devendo ser comprovada ainda a culpa do profissional [...]”.

[...] Relativamente à responsabilidade dos hospitais, casas de saúde e similares, a melhor doutrina e a reiterada jurisprudência a tem como contratual, posto que ao admitir o paciente, seja em estabelecimento pago ou gratuito, estabelece-se entre as partes um contrato, e como tal, toma o hospital por obrigação o tratamento benévolo, tanto no que se refere à saúde quanto à hospedagem. Quando o hospital firma com o paciente internado um contrato hospitalar, assume as obrigações de meios consistentes em fornecer serviços médicos (quando o facultativo a ele pertence) ou apenas em fornecer hospedagem (alojamento, alimentação) $e$ de prestar serviços paramédicos (medicamentos, instalações, instrumentos, pessoal de enfermagem, etc.). Tem-se que a autora foi atendida por seus prepostos, de forma negligente[...].

\section{Comentários}

Os profissionais de saúde e as instituições hospitalares, muitas vezes são condenados de forma solidária aos atos danosos eventualmente praticados. Em um dos casos, o hospital, apresentou contestação, denunciando à lide o médico. O Hospital foi condenado ao pagamento de indenização por danos morais no importe de 100 (cem) salários mínimos. Julgou, ainda, procedente a denunciação da lide para condenar solidariamente o médico (litisdenunciado) ao pagamento de indenização por danos morais no importe de 150 (cento e cinquenta) salários mínimos. 
Foram unânimes os posicionamentos dos Julgadores do STJ quanto aos atos técnicos praticados de forma defeituosa pelos profissionais da saúde vinculados de alguma forma ao hospital, respondendo solidariamente a instituição hospitalar e o profissional responsável, apurada a sua culpa profissional.

Houve o entendimento de que a responsabilidade seria do médico que atuou diretamente no parto, mas também é do hospital ainda que não seja empregadora do médico obstetra, devendo responder, pois, no mínimo, o hospital deveria zelar pela qualificação e capacidade dos profissionais que atuam em suas dependências, bem como supervisionar os serviços prestados em seu estabelecimento, devendo ser lembrado que a paciente não procurou tão somente o profissional da saúde, e sim o nosocômio.

- DSC D - Discurso do Sujeito Coletivo acerca da falha da prestação de serviços relação de consumo

[...] A prestação de serviço hospitalar está tipificada nas disposições dos arts. $2^{o}$ e $3^{\circ}, \S 2^{o}$, do CDC, razão por que a sua responsabilidade é objetiva, nos termos do art. 14 do CDC, o que tem como consequência do ônus da prova. A relação existente entre as partes é de consumo. O réu, como fornecedor de serviços, responde, "independentemente" da existência de culpa, pela reparação dos danos causados aos consumidores por defeitos relativos à prestação de serviços, bem como informações insuficientes ou inadequadas sobre sua fruição e riscos', conforme estabelece o art. 14 do Código de Defesa do Consumidor[...].

\section{Comentários}

$\mathrm{O}$ entendimento prevalente é que a relação existente entre as partes é de consumo. O réu, como fornecedor de serviços, responde, "independentemente da existência de culpa, pela reparação dos danos causados aos consumidores por defeitos relativos à prestação de serviços, bem como informações insuficientes ou inadequadas sobre sua fruição e riscos", conforme estabelece o art. $14^{23}$ do Código de Defesa do Consumidor. Tal dispositivo adotou a teoria da responsabilidade objetiva, sendo certo que o estabelecimento hospitalar apenas ficaria isento da responsabilidade nas hipóteses previstas nos incisos I e II, do $\S 3^{\circ}$, do citado artigo 14 .

Nos moldes do que preconizam os arts. $6^{\circ}$, VIII e 14 , caput e $\S 3^{\circ}$, do CDC, cabe ao hospital-fornecedor demonstrar a segurança e a qualidade da prestação de seus serviços, devendo indenizar o paciente-consumidor que for lesado, em decorrência de falha naquela atividade. 


\section{- DSC E - Discurso do Sujeito Coletivo acerca das provas produzidas}

[...] O prontuário médico indica que não havia plantonista obstetra do hospital na sala de pré-parto, nem na de parto, e nenhum membro da equipe do nosocômio realizou exames na parturiente antes do procedimento cirúrgico, implicando omissão de socorro, eis que não interveio no nascimento da criança.[...]

[...] o perito foi categórico em afirmar que "a aplicação do fórceps de Simpson foi correta, mas em tempo de salvar a mãe e não o feto em sua inteireza. Quando aplicado o fórceps, certamente já estava o feto em sofrimento por prolongado período expulsivo sem descida pelo canal do parto além do plano III de Hodge (cabeça encaixada)”. Desse modo, concluiu o expert do juízo que o uso do fórceps não contribuiu para o estado de saúde atual da menor, não ocorrendo erro técnico durante sua aplicação porque ausentes sinais de traumatismo fetal pela sua utilização, salientando que, na realidade os danos a menor foram ocasionados pela sua indicação tardia, tendo em conta que o que ocasionou a interrupção da oxigenação encefálica foi o hiato temporal (1 hora e 13 minutos) entre a parada de progressão em plano III de Hodge e a extração final do concepto[..].

[...] O próprio médico (f. 141-142) que acompanhou a gravidez da apelada e realizou o parto (natimorto) reconhece que "a auxiliar de enfermagem não pode fazer parto e nem pode examinar pacientes, para verificar se elas já estão ou não em trabalho de parto". A falta de condições daquele nosocômio aflora, ainda, do mesmo depoimento:... não existe médico de plantão na maternidade do hospital, razão pela qual o declarante e os outros médicos treinam as auxiliares em enfermagem para tirar os sinais vitais do feto e da gestante e detectar se estas já estão em trabalho de parto. Feita perícia, o médico perito não pôde atestar que a patologia apresentada pelo filho da autora era consequência da negligência do médico requerido. Aliás, a perícia foi clara quanto à ausência de negligência [...]. 


\section{Comentários}

A produção das provas documentais, testemunhais e periciais foi essencial para o convencimento dos julgadores, especialmente a prova técnica, a qual é realizada pelo perito médico do juízo.

Foi observado nos julgados que quando existente na prova pericial, a experimentação de danos pela pessoa e a presença do nexo de causalidade, resultou-se presente a obrigação de indenizar. Em todos os casos, a prova pericial foi elucidativa quanto ao nexo de causalidade entre a atuação dos médicos e as causas que ensejaram a responsabilização.

\section{- DSC F - Discurso do Sujeito Coletivo acerca da má prática dos procedimentos do parto natural e cesariana}

[...] o feto não se encontrava em posição adequada, e mesmo assim, optaram por realizar o parto normal, quando seria necessária a realização de cesariana, causando danos irreversíveis à saúde da criança e ao estado psicológico dos genitores[..].

[...] demora na expulsão provavelmente por falta de material adequado, além da falta de monitorização adequada do feto para a detecção de sofrimento. Falta de material necessário e imprescindível à boa condução do parto[...]

[..] Durante a realização do parto, o feto entrou em sofrimento, abrindo a boca energeticamente e aspirando material verde-escuro produzido pelo seu intestino (denominado mecônio) e excretado no líquido amniótico pelo próprio feto. O líquido contaminado com mecônio provocou o colapso dos alvéolos pulmonares [...].

[..] o médico agiu, no mínimo, negligentemente, não só por não ter dispensado a assistência necessária à parturiente, mãe do autor, consciente da posição incomum do feto, como também por ter a deixado por horas prolongadas em observação aguardando a ocorrência do parto normal[...]. 
[...] Parturiente que é encaminhada a hospital de madrugada diante dos primeiros sinais do parto, é medicada com substância para induzir o nascimento da criança e depois deixada sozinha no leito, sem o adequado acompanhamento, vindo a ser socorrida apenas com a troca de plantonistas ocorrida de manhã, quando já verificado o óbito do feto[...].

[...] O erro médico consistiu na conduta negligente do médico em não optar pelo parto cesariana, na falta de acompanhamento da frequência cardíaca do feto, retirando-se o profissional da sala de parto no momento crítico da expulsão do recém-nascido[...].

\section{Comentários}

A má prática nos procedimentos médicos abrangem elementos que podem ser extraídos da conduta culposa, ou seja, a conduta voluntária com resultado involuntário, a previsão ou previsibilidade e, por fim, a ausência de cuidado, cautela e diligência, sem a devida atenção às regras técnicas pertinentes ao seu exercício profissional.

\section{- DSC G - Discurso do Sujeito Coletivo acerca do fato da técnica}

[...]O laudo pericial concluiu que "é possivel estabelecer nexo causal entre o parto realizado e a paralisia do membro superior direito apresentada pelo filho periciando". Porém, em resposta aos quesitos formulados pelo próprio Apelante (quesitos 8 a 12 fls. 225/226), ficou suficientemente comprovado que não houve erro dos médicos. Ratificando esse entendimento, o laudo é taxativo ao concluir que os médicos atuaram com todas as precauções necessárias, incluindo a realização do procedimento que se mostrava mais adequado (parto obstétrico), e que era impossivel prever, tampouco prevenir, o dano sobrevindo ao Apelante. Destarte, a conclusão da perícia comprova que a obrigação de meio da equipe médica foi cumprida e o resultado, ainda que não esperado, não revela desacerto profissional[...].

\section{Comentários}


O fato da técnica pode ser considerado excludente de responsabilidade civil quando analisada no caso concreto, sob a ótica da jurisprudência, uma vez que não há lei regulamentando sua aplicação. Isso porque apenas se baseia nos princípios constitucionais, como a ampla defesa, igualdade e principalmente a dignidade da pessoa humana.

Elias Kallas Filho ${ }^{25}$, argumenta que o fato da técnica desqualifica o elemento culpa, ensejador da responsabilidade civil. Em alguns casos a excludente se assemelha à ausência de defeito por risco inerente, o que depende, portanto, da inevitabilidade do dano, mas não necessariamente de sua imprevisibilidade, isto é, excluirá a responsabilidade do médico quando verificada que a técnica utilizada, embora predominantemente benéfica e aprovada pela comunidade científica seja corretamente executada, mesmo sendo o dano existente.

A aplicação do fato da técnica reforça que, caso a obrigação de meio da equipe médica seja cumprida e o resultado, ainda que não seja o esperado, não poderá ser revelado "desacerto profissional".

\section{- DSC H - Ilegitimidade passiva da União}

[...] O acórdão recorrido está em contrariedade com a jurisprudência do STJ, firmada no sentido de que a União não possui legitimidade passiva nas ações de indenização por falha em atendimento médico ocorrida em hospital privado credenciado ao SUS, tendo em vista que, de acordo com a descentralização determinada pela Lei 8.080/1990, a responsabilidade pela fiscalização é da direção municipal do aludido sistema [...].

\section{Comentários}

No caso da demora no atendimento ao parto na rede pública nacional (SUS) foi concluído que a União, ré do caso, não tem legitimidade para figurar no polo passivo da ação. A ação foi julgada procedente em primeira e segunda instância, mas o STJ reformou a decisão, julgando extinta o feito sem julgamento do mérito. O posicionamento dos Ministros da Corte é unânime no sentido de ausência de responsabilidade da União acerca dos danos eventualmente causados pelos profissionais e centros de saúde relacionados ao Sistema Único de Saúde.

\section{Conclusão}

Pode-se dizer que as questões analisadas mediante os discursos dos julgadores do STJ, favorecem o estudo quali-quantitativo proposto, o qual mostrou-se um instrumento valioso para a 
geração de dados primários e secundários. Por meio da análise dos discursos, foram reveladas práticas obstétricas que ainda conflitam com os incentivos que os órgãos públicos e privados têm recorrido para reduzir o número de cesarianas. Isso ocorre, porque a vida está estritamente ligada à área obstétrica. Contudo, a bem da verdade ainda persiste nos sistemas e organizações de saúde a má gestão dos bens públicos, a falta de estrutura, a desorganização e os recursos escassos que só retardam a concretização das medidas adotadas na tentativa de humanização do parto.

É preciso reformular o modelo de assistência ao parto no Brasil e não apenas responsabilizar os médicos pelo excesso de cesarianas. Os discursos revelam discussões bastante relevantes, que podem ser repensadas como iniciativa para uma mudança gradativa nas relações entre os envolvidos no processo gestacional e puerperal, inclusive aos operadores do direito (advogados, Poder Judiciário e demais instituições) que de certa forma, aplicam a lei ao caso concreto e os profissionais da saúde obstétrica (médicos, enfermeiros), que atuam diretamente com as dificuldades enfrentadas no exercício da profissão.

O trabalho revelou resultados que sugerem identificar o predomínio das correntes jurisprudenciais da Corte, a fim de obter subsídios para as organizações de saúde, sobretudo minimizar o ativismo judicial e os riscos decorrentes da má-prática médica obstétrica, reduzir custos provenientes das altas indenizações e incentivar a humanização, a qualidade e excelência na assistência ao parto.

\section{Referências}

1. Brasil. Ministério da Saúde. DATASUS. Nascidos vivos no Brasil, 2013.. Disponivel em: http://tabnet.datasus.gov.br/cgi/deftohtm.exe?sinasc/cnv/nvuf.def.

2. Brasil. Fiocruz - Nascer no Brasil. Pesquisa revela número excessivo de cesarianas; 2014. Disponível em http://portal.fiocruz.br/pt-br/content/pesquisa-revela-numero-excessivo-decesarianas-no-pais.

3. Sass N, Hwang S. Dados epidemiológicos, evidências e reflexões sobre a indicação de cesariana no Brasil. Departamento de Obstetrícia, Universidade Federal de São Paulo — Escola Paulista de Medicina (Unifesp-EPM), Diagn Tratamento. 2009;14(4):133-7. 
4. Villar J, Valladres E, Wojdyla D, et al. Cesarean delivery rates and pregnancy outcomes: the 2005 WHO global survey on maternal and perinatal health in Latin America. Lancet. 2006;367(9525):1819-29.

5. Luis P, Paula A, Pereira E, Orlando A, Schilithz C. Sampling design for the Birth in Brazil : National Survey into Labor and Birth. Desenho da amostra Nascer no Brasil, 2014 1-10. Disponível em: http://www.scielo.br/pdf/csp/v30s1/0102-311X-csp-30-s1-0049.pdf.

6. Eua O, Am N, Unido R. Editorial A questão das cesarianas. Rev Bras Ginecol Obstet. 2005;27(51):571-4.

7- Diniz CSG. Humanização da assistência ao parto no Brasil: os muitos sentidos de um movimento. Cien Saude Colet. 2005;10(3):627-37.

8. Porto AMF, Amorim MMR, Souza ASR. Assistência ao primeiro período do trabalho de parto baseada em evidências. Femina. 2010;38(10):527-37.

9. Clinical guidelines. Intrapartum care - care of healthy women and their babies during childbirth. London: National Collaborating Centre for Women's and Childrens's Health. Royal College of Obstetricians and Gynaecologists; 2007.

10. Hofmeyr GJ, Hannah M, Lawrie TA. Planned caesarean section for term breech delivery. Cochrane Database Syst Rev. 2015 Jul 21;7:CD000166. doi: 10.1002/14651858.CD000166.pub2. Review. PubMed PMID: 26196961.

11. Alfirevic Z, Milan SJ, Livio S. Caesarean section versus vaginal delivery for preterm birth in singletons. Cochrane Database Syst Rev. 2013 Sep 12;9:CD000078. doi: 10.1002/14651858.CD000078.pub3. Review. PubMed PMID: 24030708.

12. Cardoso PO, Alberti LR, Petroianu A. Morbidade neonatal e maternas relacionada ao tipo de parto. Cien Saude Colet. 2010;15(2):427-35

13. Hannah ME, Whyte H, Hannah WJ, Hewson S, Amankwah K, Cheng M, Gafni A, Guselle P, Helewa M, Hodnett ED, Hutton E, Kung R, McKay D, Ross S, Saigal S, Willan A; Term Breech 
Trial Collaborative Group. Maternal outcomes at 2 years after planned cesarean section versus planned vaginal birth for breech presentation at term: the international randomized Term Breech Trial. Am J Clin Exp Obstet Gynecol. 2004 Sep;191(3):917-27. PubMed PMID: 15467565.

14. Sandro A, Souza R, Maria M, Amorim R, Maria A, Porto F. Indicações de cesariana baseadas em evidências: parte II. Femina. 2010;38(9):459-68.

15. Piazza MJ. Medicina defensiva e os ginecologistas e obstetras. Femina, 2012; 40 (1):1-4. Disponivel em: http://www.febrasgo.org.br/site/wp-content/uploads/2013/05/Femina-v40n1_14.pdf.

16. La responsabilidad civil por defectuosa prestación de asistencia sanitaria al parto; 2012. Bliblioteca Unirioja. Disponível em: http://biblioteca.unirioja.es/tfe_e/TFE000236.pdf.

17. Eroglu S., Toprak S., Urgan O, MD, Ozge E. Onur, MD, Arzu Denizbasi, MD, Haldun Akoglu, MD, Cigdem Ozpolat, MD, Ebru Akoglu M. Impacto de los dictámenes periciales del cendes en los procesos judiciales. Saudi Med J. 2012;33:3-8.

18. Federação Brasileira das Associações de Ginecologia e Obstetrícia - FEBRASGO. Erro Médico no dia a dia da ginecologia e obstetrícia; 2014. Disponível em: http://www.febrasgo.org.br/site/?p=2019.

19. Nomura Seizo ; Zugaib, Marcelo RMY; M. O perfil dos médicos denunciados que exercem ginecologia e obstetrícia no Estado de São Paulo. Rev Assoc Med Bras. 2006. 52:144-7. Disponível em: http://www.scielo.br/pdf/ramb/v52n3/a02v52n3.pdf.

20. Lefevre F, Lefevre AMC. O sujeito coletivo que fala. Interface - Comun Saúde, Educ. 2006;10(20):517-24.

21. Lefevre AMC, Crestana MF, Cornetta VK. A utilização da metododologia do discurso do sujeito coletivo na avaliação qualitativa dos cursos de especialização "Capacitação e Desenvolvimento de Recursos Humanos em Saúde-CADRHU", São Paulo - 2002. 200312(2):6875. Disponivel em:: http://www.revistas.usp.br/sausoc/article/view/7099/8570. 
22 - Mota, Aline Veras Leite. Análise do Discurso da Jurisprudência do STJ nas indenizações por erro médico: impacto no sistema de saúde. [dissertação de mestrado]. Ribeirão Preto - Faculdade de Medicina de Ribeirão Preto - FMRP/USP, 2015.

23 - Brasil. Lei CDC - Lei no 8.078 de 11 de Setembro de 1990 dispõe sobre a proteção do consumidor e dá outras providências. Art. 14. O fornecedor de serviços responde, independentemente da existência de culpa, pela reparação dos danos causados aos consumidores por defeitos relativos à prestação dos serviços, bem como por informações insuficientes ou inadequadas sobre sua fruição e riscos. $\$ 1^{\circ} \mathrm{O}$ serviço é defeituoso quando não fornece a segurança que o consumidor dele pode esperar, levando-se em consideração as circunstâncias relevantes, entre as quais: II - o resultado e os riscos que razoavelmente dele se esperam; III - a época em que foi fornecido. $\S 3^{\circ}$ O fornecedor de serviços só não será responsabilizado quando provar: I - que, tendo prestado o serviço, o defeito inexiste; II - a culpa exclusiva do consumidor ou de terceiro, 1990. Disponível em: http://www.planalto.gov.br/ccivil_03/leis/L8078.htm.

24- Brasil. Constituição Federal do Brasil. Art. 37, § $6^{\circ}$ As pessoas jurídicas de direito público e as de direito privado prestadoras de serviços públicos responderão pelos danos que seus agentes, nessa qualidade, causarem a terceiros, assegurado o direito de regresso contra o responsável nos casos de dolo ou culpa., 1988. Disponível em: http://www.planalto.gov.br/ccivil_03/Constituicao/Constituicao.htm.

25 - Kallas Filho, Elias. O fato da técnica: excludente da responsabilidade civil do médico. R. Dir. sanit, Brasil, v. 14, n. 2, p. 137-151; 2013. ISSN 2316-9044. Disponível em: <http://www.revistas.usp.br/rdisan/article/view/63998>. 


\section{Apêndice I - Formulário Quantitativo}

\section{Dados gerais}

1.1- $\quad \mathrm{N}^{\mathrm{o}}$ do caso:

1.2- $\quad \mathrm{N}^{\mathrm{o}}$ do acórdão:

1.1- Vara/Comarca/Estado:

1.2- Ano do julgamento:

1.3- Julgador:

1.4- Liminar: ( ) Sim ( ) Não

1.5- Tutela antecipada: ( ) Sim ( ) Não

\section{Partes}

2.1- $\mathrm{N}^{\mathrm{o}}$ do autor:
2.2- Autor: ( ) Mãe
( ) Recém-Nascido
( ) Outros

2.3- Sexo do paciente:

2.4- Beneficiário da Justiça Gratuita: （ ) Sim ～～） Não

2.5- Réus:

2.6- Solidariedade passiva:

( ) Hospital ( ) Operadora de plano de saúde ( )

Ente Público ( ) Outros

2.7 - ( ) Hospital Público

( ) Hospital Particular

2.8-Advogado: ( ) Particular ( ) Defensoria ( ) Outros

\section{Fatos e Provas}

3.1- Motivo da ação:

3.2- Dano:

3.3- ( ) Cirúrgico

3.4- ( ) Parto Natural

( ) Clínico

3.5- Situação do paciente após o dano

( ) Cesáreo

( ) Outras

3.5- Qualidade da prova: （ ) Documental （） Laboratorial （） Pericial Judicial

( ) Pericial Particular

\section{Decisões}

4.1- Sentença:

4.2- $\quad$ Acórdão $2^{\circ}$ grau: 
4.3- Acórdão STJ:

4.4- Reú Condenado:

4.5- Motivo da condenação:

4.6- Valor da Condenação: 


\section{Apêndice II - Formulário Qualitativo}

1- Presença dos pressupostos (fato, dano e nexo causal)

2- $\quad$ Responsabilidade civil do hospital;

3- Responsabilidade civil do médico;

4- $\quad$ Responsabilidade civil do Poder Público (União, Estado, Município);

5- $\quad$ Aferição de culpa;

6- Responsabilidade solidária;

7- $\quad$ Origem dos danos causados;

8- Dano Moral;

9- Dano Material;

10- Prova técnica;

11- Fundamentos legais, doutrinários e jurisprudenciais;

12- $\quad$ A importância do elemento probatório

13- Principais discussões travadas em juízo;

14- Principais argumentos utilizados pelas instituições de saúde;

15- Principais argumentos utilizados pelos profissionais de saúde; 


\section{Glossário jurídico}

Ação - ato preliminar da formação do processo judicial.

Acórdão - julgamento prolatado pelos órgãos colegiados (turma de magistrados) dos tribunais e dos Tribunais Superiores como o STJ e o STF.

Agravo regimental - recurso judicial existente nos tribunais com o intuito de provocar a revisão de suas próprias decisões.

Despacho denegatório de recurso - decisão que não admite recurso especial, ou seja, não permite que o Recurso Especial seja julgado no STJ.

Apelação - recurso interposto contra a sentença em que a(s) parte(s) pede(m) o reexame de uma decisão, a fim de se obter a sua reforma, sua modificação ou sua invalidação.

Ementa - consiste em uma breve apresentação do conteúdo do acórdão que contem o resumo do tema discutido.

Juízo de admissibilidade - é a análise dos requisitos processuais que a lei impõe e, sendo atendidos, o juízo de mérito será apreciado com base na matéria recorrida.

Jurisprudência - conjunto das decisões e interpretações das leis pelos tribunais acerca de um mesmo assunto formando um entendimento comum. É formada por decisões uniformes e reiteradas dos tribunais.

Autor - Pessoa, órgão ou entidade que propõe a ação judicial. É a parte que invoca o direito.

Réu - Pessoa, órgão ou entidade que sofre a ação judicial. É a parte contra quem se invoca um direito.

Primeira instância - primeiro órgão da Justiça ao qual o cidadão deverá dirigir um pedido de solução de conflito. 
Segunda instância - segundo órgão da Justiça ao qual o cidadão poderá recorrer de decisão proferida em $1^{a}$ instância.

Sentença - ato do juiz que implica alguma das situações previstas nos artigos 267 e 269 do Código de Processo Civil. Decisão do juiz que põe fim a um processo na $1^{\mathrm{a}}$ Instância, mas sobre a qual ainda cabe recurso ao Tribunal de $2^{\mathrm{a}}$ Instância. 
Gráfico 3 - Organograma do Poder Judiciário

\section{ORGANOGRAMA DO PODER JUDICIÁRIO}

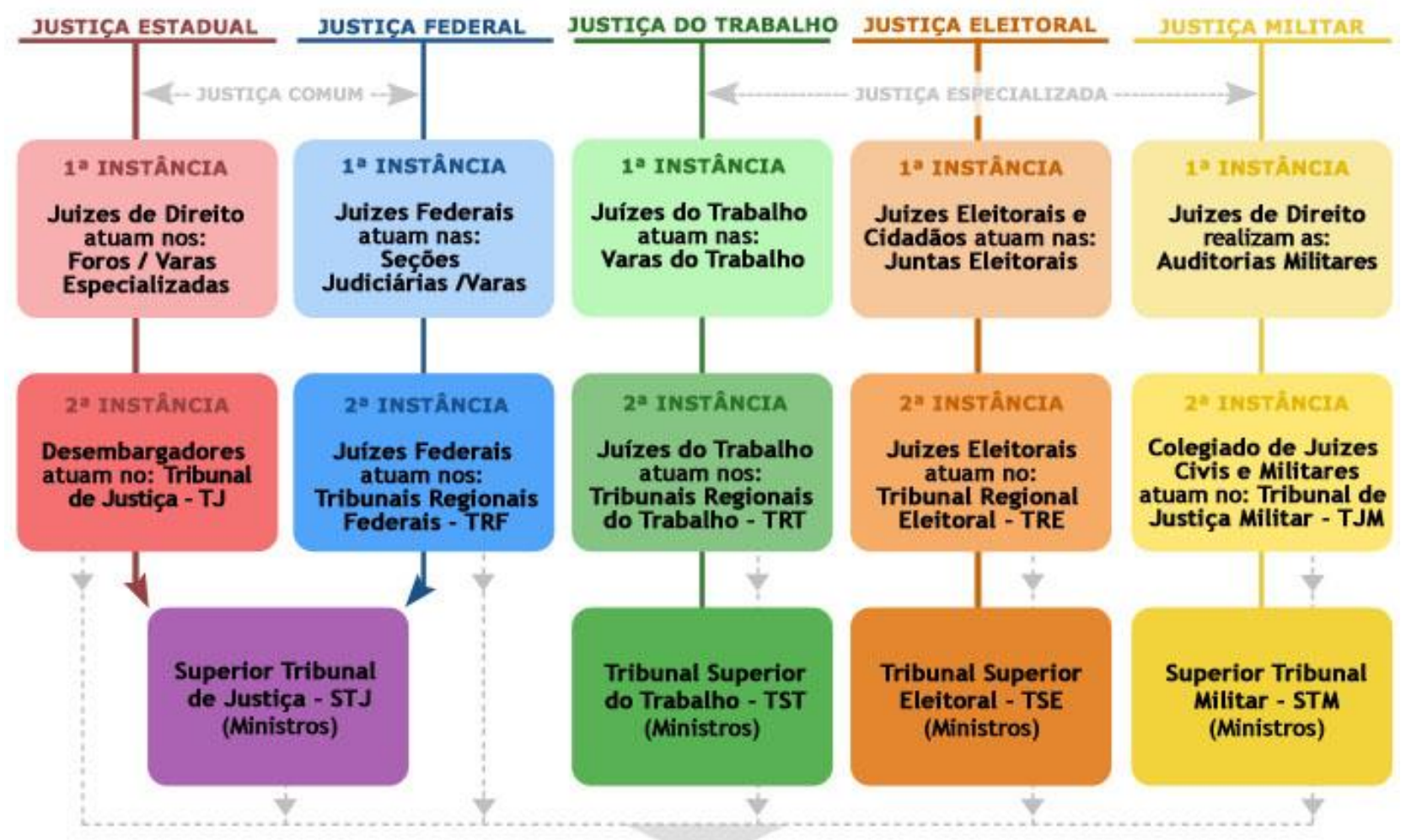

SUPREMO TRIBUNAL FEDERAL - STF

Ministros atuam no STF em casos que envolvam

lesão ou ameaça à Constituição Federal

(D) www.guiadedireitos.org

Organograma

do

Poder

Judiciário.

Disponível

em:

http://www.guiadedireitos.org/images/stories/organograma-judiciario-inv-m.jpg. Acesso em 11 mai, 2015. 